\title{
Minor impacts of major volcanic eruptions on hurricanes in dynamically-downscaled last millennium simulations
}

\author{
Brandon N. Benton ${ }^{1} \cdot$ Marc J. Alessi $^{1,2}$ (D) Dimitris A. Herrera ${ }^{1,3} \cdot$ Xiaolu Li $^{1} \cdot$ Carlos M. Carrillo $^{1} \cdot$ Toby R. Ault $^{1}$
}

Received: 29 March 2021 / Accepted: 12 November 2021 / Published online: 13 February 2022

(c) The Author(s) 2022

\begin{abstract}
The effects of volcanic eruptions on hurricane statistics are examined using two long simulations from the Community Earth System Model (CESM) Last Millennium Ensemble (LME). The first is an unforced control simulation, wherein all boundary conditions were held constant at their $850 \mathrm{CE}$ values $\left(\mathrm{LME}_{\text {control }}\right)$. The second is a "fully forced" simulation with time evolving radiative changes from volcanic, solar, and land use changes from $850 \mathrm{CE}$ through present $\left(\mathrm{LME}_{\text {forced }}\right)$. Large tropical volcanic eruptions produce the greatest change in radiative forcing during this time period, which comprise the focus of this study. The Weather Research and Forecasting (WRF) model is used to dynamically downscale 150 control years of $\mathrm{LME}_{\text {control }}$ and an additional 84 years of $\mathrm{LME}_{\text {forced }}$ for all mid-latitude volcanic eruptions between 1100 and $1850 \mathrm{CE}$. This time period was selected based on computational considerations. For each eruption, 2 years are dynamically downscaled. 23 of these volcanic eruptions are in the Northern Hemisphere and 19 are in the Southern Hemisphere. The effectiveness of the downscaling methodology is examined by applying the same downscaling approach to historical ERA-I reanalysis data and comparing the downscaled storm tracks and intensities to the International Best Track Archive for Climate Stewardship (IBTrACS) database. Hurricane statistics are then computed from both the downscaled control and downscaled forced LME simulations. Results suggest moderate effects on hurricanes from the average of all northern hemisphere eruptions, with the largest effects being from the volcanoes with the most aerosol forcing. More specifically, reductions in hurricane frequency, intensity, and lifetime following northern hemisphere eruptions are apparent. Strong evidence is also shown for correlation between eruption strength and changes in these diagnostics. The aggregate effect from both northern and southern hemisphere eruptions is minor. While reductions in frequency, intensity, and lifetime from northern hemisphere eruptions occur, the opposite effect is observed from southern hemisphere eruptions.
\end{abstract}

Keywords Hurricanes $\cdot$ Volcanoes $\cdot$ Solar geoengineering $\cdot$ Last millennium ensemble

\section{Introduction}

Hurricanes threaten human lives and livelihoods, inflict severe damage to property, and incur billions of dollars in economic losses and recovery efforts. From 1992 through

Brandon N. Benton

bnb32@cornell.edu

Toby R. Ault

toby.ault@cornell.edu

1 Cornell University, Ithaca, NY, USA

2 Present Address: Colorado State University, Fort Collins, CO, USA

3 Present Address: Instituto Geográfico Universitario, Universidad Autónoma de Santo Domingo, Santo Domingo 10103, Dominican Republic
2011, these events alone caused $42 \%$ of the catastropheinsured losses in the United States (King et al. 2013). The disruption from these extreme weather events will likely increase with rising coastal populations and increasing value of infrastructure in coastal areas (Knutson et al. 2010). Furthermore, anthropogenic climate change is already worsening and expected to further increase average sea surface temperatures (SSTs) and sea level (IPCC 2018; Kossin et al. 2020). There is growing interest in determining if modifications to the incoming flux of solar radiation could potentially offset key impacts expected to occur from rising global temperature (Msadek et al. 2013). Whether or not such strategies are pursued, it is critical to understand the relationship between hurricane statistics and climate responses to past radiative forcings to help characterize the full range of plausible future anthropogenic influences on hurricane activity. 
The underlying relationship between hurricanes, radiative forcing, and climate change remains an area of active inquiry (Ting et al. 2015; Elsner 2006; IPCC 2014). Several modeling studies have suggested that, in general, future storms may pose more severe threats to human well-being, infrastructure, and the economy (IPCC 2014). For example, Villarini and Vecchi (2013) and Emanuel (2013) used data from the Coupled Model Intercomparison Project 5 (CMIP5) ensemble to evaluate storm intensity under climate change. Such studies suggest that the number and intensity of the largest storms (e.g., category 4 and 5 hurricanes) will increase in a warmer climate due primarily to an increase in SST. Recent evidence (Kossin et al. 2020) demonstrates that TCs have significantly increased in intensity, though this may be due to changing observational methodologies (Vecchi et al. 2021). Furthermore, Wang et al. (2018) and Strauss et al. (2021) have shown clear evidence for anthropogenic influence on hurricane precipitation and flooding, respectively.

While we are interested in the relationship between volcanic eruptions and hurricanes for its own sake, eruptions of the recent past and last millennium may also provide a glimpse of the risks associated with "solar geoengineering" (SG), which has received increasing attention as a possible strategy for slowing down the rate of global warming from greenhouse gas emissions (Govindasamy and Caldeira 2000; Caldeira and Wood 2008; Kravitz et al. 2014; MacMartin et al. 2019). That is, if global greenhouse gas reduction efforts are insufficient in the coming decades, some researchers argue that interventions to the climate system may be preferable to allowing global temperatures to increase (Govindasamy and Caldeira 2000; Caldeira and Wood 2008; Kravitz et al. 2014; MacMartin et al. 2019). While there are numerous SG strategies, stratospheric aerosol injection (SAI) in particular mimics large volcanic eruptions (Jones et al. 2017; Crutzen 2006). Fundamentally, SAI decreases the total amount of sunlight reaching the surface, which shares some similarity with the effect of stratospheric aerosol injections from volcanic eruptions. In the stratosphere, chemical and micro-physical processes convert $\mathrm{SO}_{2}$ into sub-micrometer sulfate particles. The process has been observed in volcanic eruptions (Wilson et al. 1993; Bluth et al. 1992). Although the particle sizes of artificial aerosols are not necessarily the same as volcanic aerosols, the injection rate of artificial aerosols can be designed to roughly match volcanic radiative forcing (Lacis and Mischenko 1995). In addition to the micro-physical differences between SAI and volcanic eruptions, differences in climate response can result from whether SAI is pulsed or sustained and also from injection location. Volcanic eruptions more closely match a pulsed SAI forcing, and the effects of a sustained forcing can be significantly different (Duan et al. 2019). Thus caution should be taken when extrapolating climate responses of volcanic eruptions to climate responses of SAI in general. The similarities between SAI and eruptions mentioned here only extend as far as the SAI regime mimics the location and duration of the eruptions.

Volcanic eruptions result in an increased reflection of solar radiation, which can strongly impact global temperatures, circulation patterns, and water cycles (Mass and Portman 1989; Robock 2000; Swingedouw et al. 2017). Changes in tropical sea surface temperature from SAI and volcanic eruptions would also similarly alter the position of the Inter Tropical Convergence Zone (ITCZ). For example, asymmetric volcanic forcings (e.g., volcanic aerosols being concentrated in the stratosphere of one hemisphere) alter the position of the ITCZ for at least one year following an eruption (Yang et al. 2019; Pauseta et al. 2019; Jones et al. 2017). These effects could potentially be even longer lasting if coupled interactions between the ocean and atmosphere are engaged (Colose et al. 2016; Raible et al. 2016; Schurer et al. 2013, 2014). Given that hurricanes are sensitive to the regions where moisture convergence occurs, it follows that such radiative effects on the global circulation could influence hurricane statistics.

The historical record only provides a few clues about the effect of volcanic eruptions on hurricanes or tropical cyclones (TCs). Nevertheless, modeling studies suggest that a reduction in TC accumulated energy, TC duration, and lifetime maximum intensity occurs following a volcanic eruption due to a decrease in SST and increase in upper tropospheric/lower stratospheric temperature (Evan 2012), all of which decreases TC thermodynamic efficiency estimates (Emanuel et al. 2013). The asymmetric increase in stratospheric aerosols occurs in the hemisphere in which the eruption took place, modifying the sea surface temperature gradient (Haywood et al. 2013). This gradient shifts the location of the Inter-tropical Convergence Zone (ITCZ) to the opposite hemisphere of the eruption (Haywood et al. 2013), which hinders hurricane development in the volcano's own hemisphere due to a decrease in convection and increase in wind shear. In fact, after the northern hemisphere eruptions of Mount Pinatubo (1991) and El Chichón (1982), North Atlantic TC activity decreased, while TC activity increased following the southern hemisphere eruption of Agung (1964) (Evan 2012; Guevara-Murua et al. 2015). More recently, Camargo and Polvani (2019) found no robust reduction of North Atlantic tropical cyclone activity in recent observations or reanalysis. A reduction in potential intensity (PI) is observed in CMIP5 and CESM large-ensemble historical simulations after volcanic eruptions, though the decrease might be overestimated due to model bias.

Comparisons between all-forcing and single-forcing last millennium model simulations, as well as multiproxy paleoclimate constructions, have shown that large volcanic eruptions were the dominant forcing during the pre-industrial 
record (Schurer et al. 2013, 2014). Studies have also shown that large tropical volcanic eruptions may have long-lasting influences on the Atlantic multi-decadal oscillation and lead to El Niño-like warming in the cold season after the eruption (Otto-Bliesner et al. 2016). Such impacts could, in turn, affect hurricane statistics because these large-scale modes help govern, in part, the frequency and intensity of storms occurring in any given year.

Attempts to use paleoclimate indicators of past events (i.e., paleotempestology) are limited by the paucity of appropriate archives and proxies (Liu et al. 2008; Mann et al. 2009; Donnelly et al. 2015). Importantly, most paleorecords are commonly constrained to certain geographic areas and currently provide limited information from other regions also commonly affected by TCs, such as the Caribbean (Oliva et al. 2018). The use of paleotempestological records is further limited because it is not possible to fully reconstruct the tracks and lifetime of past TCs, most of which occur over the ocean (Emanuel 2005). These limitations preclude the extensive use of such data to evaluate the effects of major volcanic eruptions on TC activity (Oliva et al. 2018; Yan et al. 2015; Korty et al. 2012).

Hurricanes are mesoscale features of the tropical circulation, and as such they depend critically on quantities that are typically unresolvable in the coarse resolution grid of general circulation models (GCMs), which typically have nominal horizontal resolutions on the order of 50-200 km. For example, the resolution of the CESM simulation used here is $1.9^{\circ} \times 2.5^{\circ}$ which is roughly $211 \mathrm{~km}$ by $278 \mathrm{~km}$ at the equator. In order to overcome this limitation, authors typically follow one of three following approaches. The first approach is relatively simple, and entails calculating thermodynamic metrics like PI at the native (coarse) resolution of GCM output, which shows the maximum possible TC intensity given a vertical sounding (Wang et al. 2018; Emanuel and Nolan 2004; Tang and Camargo 2014; Bister and Emanuel 2002). A recent study (Yan et al. 2018) used the last millennium ensemble (LME) to determine the theoretical effects of volcanic eruptions during the last 1000 years on PI. The authors found a significant relationship lasting up to 3 years post-eruption, but also "divergent" responses at the mid and high latitudes to the volcanic forcing. While this approach is computationally efficient, it does not explicitly simulate TCs.

A second approach uses a statistical method, coupling synthetic tracks with an axisymmetric hurricane model to downscale GCM output (Emanuel 2006; Korty et al. 2017). This approach is computationally lightweight, allowing for an investigation of long-term variability in fully coupled GCM simulations of the last millennium (Kozar et al. 2013). While this method has a high spatial resolution in the vicinity of the eyewall, the model is limited due to being axisymmetric and a hurricane being unable to feedback on environmental conditions supplied to it.
The third approach employs a regional model to dynamically downscale GCM output (Knutson et al. 2008). Dynamical downscaling typically requires high performance computing infrastructure as well as boundary conditions from the "parent" GCM at six hourly temporal resolution. It is therefore much more computationally expensive than the other two methods, but it provides greater insight into the storms that would have occurred in each GCM framework if it were run with sufficiently high spatial resolution. Dynamical downscaling has been widely used to evaluate hurricane statistics during the twentieth and twenty-first century (Emanuel 2013), but it has not been widely adapted to the last millennium modeling context.

In this study, we use WRF to dynamically downscale output from the LME to analyze the effect of volcanic eruptions on hurricane intensity and lifetime. While not a perfect analog to SAI, eruptions are important for understanding physical mechanisms and validating models used in projecting the climate response to a possible SAI regime. Understanding the effects of volcanic eruptions on hurricane dynamics during the last millennium can therefore yield some insight into the possible (unintended) effects of SAI on these hazards.

\section{Data and methods}

We dynamically downscale 234 total years from two members of the "Last Millennium Ensemble" (Otto-Bliesner et al. 2016) with high resolution temporal output. The LME consists of over two dozen fully forced and single forcing experiments from the record spanning $850 \mathrm{CE}$ to 2005. The LME was used because it provided an extensive readily available dataset which could be easily downscaled. While monthly data was archived for most of the members of the LME, two simulations produced sufficiently high temporal output to allow for high resolution dynamical downscaling using a regional model. One of these runs was a fully forced last millennium simulation, and the other was a long control simulation with time invariant boundary conditions. We further evaluate the strengths and limitations of our methodology by comparing downscaled reanalysis data to an historical database of hurricane tracks and intensities. The details of this approach are described below.

\subsection{Data}

\subsubsection{Last millennium ensemble}

Output from only two members of the LME were archived at sufficiently high temporal resolution to be used as boundary conditions for WRF: a fully-forced simulation with time varying boundary conditions $\left(\mathrm{LME}_{\text {forced }}\right)$ and a pre-industrial 
control simulation with time invariant boundary conditions $\left(\mathrm{LME}_{\text {control }}\right)$. Both simulations were run from 850 to 2005 CE using the Community Earth System Model (CESM) version 1.1, with the Community Atmosphere Model (CAM) version 5 . The resolution of the atmosphere and land grids are nominally $\sim 2^{\circ}$ and $\sim 1^{\circ}$ for ocean and sea ice grids. While both runs were spun up for 200 years under control conditions prior to $850 \mathrm{CE}, \mathrm{LME}_{\text {forced }}$ was forced with the transient evolution of solar intensity, volcanic emissions, greenhouse gases, aerosols, and land-use conditions, as well as insolation changes from planetary orbit and tilt. In the $\mathrm{LME}_{\text {control }}$ the boundary conditions were simply held fixed at their pre-industrial levels, thus providing an unforced baseline for evaluating changes in hurricane statistics following large volcanic eruptions.

\subsubsection{ERA-I and IBTrACS}

The native $2^{\circ}$ resolution of CAM5 in the LME simulations would make it impossible to resolve hurricanes, hence we cannot evaluate the reliability of our downscaling methodology (see Sect. 2.2.1) with LME data alone. We therefore also downscaled the ERA-Interim (ERA-I) (Dee et al. 2011) reanalysis data to retrospectively predict historical hurricanes, then compared those predictions against the International Best Track Archive for Climate Stewardship (IBTrACS) (Knapp et al. 2010) database. ERA-I comprises a reanalysis dataset starting in 1979 and is available until August 2019. It uses four-dimensional variational data assimilation (4DVAR), yielding a significant advantage over reanalysis products using 3DVAR. This improves asynoptic data handling and allows for the influence of an observation to be more strongly controlled by model dynamics (Schenkel and Hart 2011). This data assimilation method is coupled with the ECMWF Integrated Forecast Model (IFS) to extrapolate fields between observations.

\subsection{Methods}

\subsubsection{Dynamical downscaling}

We used WRF version 3.9 (WRFV3.9) (Skamarock et al. 2008) to dynamically downscale archived data from LME simulations with the physics schemes shown in Table 1. We also turned on heat and moisture surfaces fluxes (isfflx $=1$ ) and modified exchange coefficients $\mathrm{Cd}$ and $\mathrm{Ck}$ according to surface winds (isftcflx $=1$ ). The physics schemes were selected to satisfy a $15 \%$ difference threshold imposed between downscaled ERA-I and IBTrACS, as quantified by our diagnostics suite.

WRF was run for a total of 234 simulation years over a domain spanning the North American sector from $130^{\circ} \mathrm{W}$ to $15^{\circ} \mathrm{E}$ and the equator to $55^{\circ} \mathrm{N}$, allowing us to identify
Table 1 WRF physics parameterizations used for downscaling

\begin{tabular}{lllc}
\hline Physics scheme & Name & Parameter & Value \\
\hline (1) Micro-physics & WSM6 & mp_physics & 6 \\
(2) PBL & YSU & bl_pbl_physics & 1 \\
(3) Convection & Kain-Fritsch & cu_physics & 1 \\
$\begin{array}{l}\text { (4) Longwave radia- } \\
\text { tion }\end{array}$ & RRTMG & ra_lw_physics & 4 \\
$\begin{array}{ll}\text { (5) Shortwave radia- } \\
\text { tion }\end{array}$ & RRTMG & ra_sw_physics & 4 \\
(6) Land surface & Noah & sf_surface_physics & 2 \\
(7) Surface layer & MM5 similarity & sf_sfclay_physics & 91 \\
(8) Ocean & Mixed-layer & sf_ocean_physics & 1 \\
\hline
\end{tabular}

(1) WRF single-moment 6-class (WSM6) for micro-physics (Hong and Lim 2006), (2) Yonsei University (YSU) for PBL (Hong et al. 2006), (3) Kain-Fritsch for convection (Kain, 2004), (4, 5) rapid radiative transfer model with greenhouse gases (RRTMG) for longwave and short-wave radiation (Iacono et al. 2008), (6) Noah for land surface (Tewari et al. 2004), (7) fifth generation mesoscale model for surface layer (Paulson 1970; Dyer and Hicks 1970; Webb 1970), and (8) simple mixed-layer for ocean (Pollard et al. 1973)

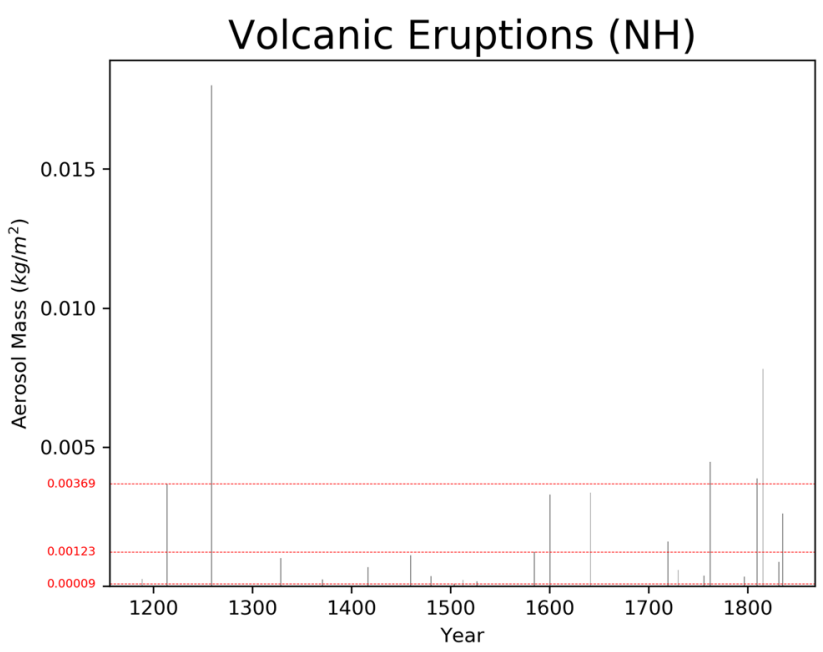

Fig. 1 Aerosol mass signals for volcanic eruptions from 1150 to 1850 CE in the Northern Hemisphere. The minimum, 10th largest, and 5th largest signals are shown with dashed lines. All signals were selected as "all NH eruptions" years for this study

and track TCs in both the Atlantic and Eastern Pacific, even after making landfall in North America. In comparing $\mathrm{LME}_{\text {control }}$ and $\mathrm{LME}_{\text {forced }}$ we focused on the effect of aerosol forcing from volcanic eruptions. The aerosol mass signals from volcanic eruptions from 1100 to $1850 \mathrm{CE}$ are shown in Fig. 1, which is described in detail in Gao et al. (2008). We selected the top 42 eruptions based on peak aerosol mass signal from $\mathrm{LME}_{\text {forced }}$ and ran WRF for two years after each of these eruptions (84 simulation years total). $\mathrm{LME}_{\text {control }}$ was run using WRF for 150 years from 1000 to 1150 to provide a sufficient sample of non-volcanic natural variability. The 
two year window after eruptions was selected because the residence time of stratospheric aerosols is around one to two years (Crutzen 2006), and individual large eruptions produce global or hemispheric cooling for an average of two or three years (Robock 2015). The $\mathrm{LME}_{\text {control }}$ run was ensured to have sufficient length by analyzing the SST signal in frequency space (Fig. 2). This analysis shows that using 100 years of control data is sufficient to ensure we are not missing any low frequency variability.

We elected to use a horizontal grid spacing $(\Delta \mathrm{X})$ of $30 \mathrm{~km}$. The $30 \mathrm{~km}$ spacing represents a compromise between our competing requirements for high resolution output and a large sample size; each downscaled year used approximately 2000 core hours on the Cheyenne supercomputer totaling about 500,000 core hours for all years. While the $30 \mathrm{~km}$ resolution is somewhat coarse for resolving certain features of hurricanes, decreasing the resolution further to $10 \mathrm{~km}$ was much too expensive. The threefold increase in spatial resolution would have translated into more than a tenfold increase in core hours, or a tenfold reduction in the number of years simulated. All data from the LME were prepared for WRF using the procedure and code described in (Bruyere et al. 2015).

In our work, 6-hourly ERA-I data was also downscaled in WRF (using the same domain and $30 \mathrm{~km}$ resolution as the downscaled LME simulations) from 1995 to 2005 and compared to the IBTrACS database for the same record. The comparison was made using the suite of diagnostics described in Sect. 2.2.3.

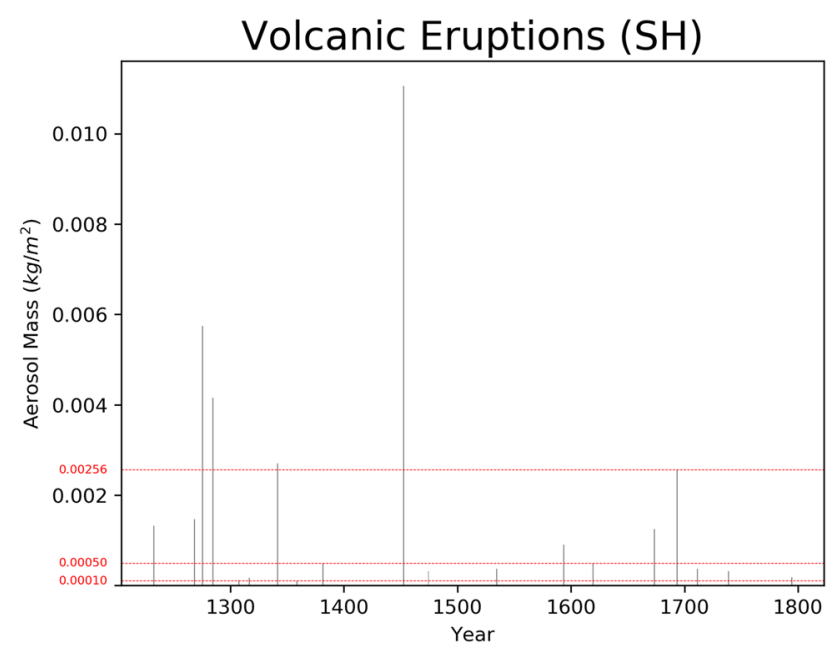

Fig. 2 Aerosol mass signals for volcanic eruptions from 1150 to 1850 $\mathrm{CE}$ in the Southern Hemisphere. The minimum, 10th largest, and 5th largest signals are shown with dashed lines. All signals were selected as "all SH eruptions" years for this study

\subsubsection{Tracking tropical cyclones with TSTORMS}

We applied the TSTORMS (Zhao et al. 2009) tracking software, developed and supported by GFDL, to analyze the results of downscaling. This routine uses minimum pressure and maximum vorticity criteria to identify cyclones. Events are stored as "storms" if they satisfy the following conditions for at least a preset number of days (ndays): (1) That the maximum vorticity location is within a threshold radius (rcrit) of the minimum pressure location, (2) that the core temperature of the cyclone is higher than outside of the core by a threshold difference (twccrit) and (3) the difference in vertical distance between pressure levels at $200 \mathrm{hPa}$ and $1000 \mathrm{hPa}$ outside and inside the core exceeds a threshold value (thickcrit).

As described in Walsh et al. (2015) and Zhao et al. (2009), tracking results are sensitive to the details of the tracking scheme that is employed and especially the threshold values selected for identifying storms (Horn et al. 2014). To identify sensitivity to threshold values, we conducted a limited parameter sweep to determine optimal threshold values. We calculated the difference between ERA-I downscaled output and IBTrACS data, for each set of parameters, using the diagnostics described in Sect. 2.2.3. We used the set of parameters that achieved the minimum difference of $\sim 13.5 \%$. This parameter set was rcrit $=1.5^{\circ}$, twccrit $=1.0^{\circ} \mathrm{C}$, thickcrit $=50 \mathrm{~m}$, and ndays $=2$.

\subsubsection{Diagnostics}

Once hurricanes were identified in our downscaled LME data using TSTORMS, we calculated 19 diagnostic metrics to evaluate differences in the statistics of storms in $\mathrm{LME}_{\text {control }}$ and those occurring after large eruptions in $\mathrm{LME}_{\text {forced }}$. The diagnostics consist of 10 storm distributions and 9 calculations of the fraction of the total number of storms with a certain range of values (e.g., fraction of storms with minimum pressure between 1020 and $980 \mathrm{hPa}$ ). We calculated the 10 distribution diagnostics as follows: the fraction of storms vs (1) month, (2) year, (3) latitude, (4) longitude, (5) maximum wind speed, (6) minimum pressure, (7) decay time from maximum wind speed, (8) decay time from minimum pressure, (9) power dissipation index (PDI), and (10) accumulated cyclone energy (ACE). For example, (5) is a plot of the fraction of storms with a specific maximum wind speed. The final 9 diagnostics include the fraction of storms within (11) May to November, (12) 0-25 N latitude, (13) 100-50 W longitude, (14) 1020-980 hPa pressure, (15) 0-40 m/s maximum wind speed, (16) $0-100 \mathrm{~h}$ decay time from maximum wind speed, (17) $0-100 \mathrm{~h}$ decay time from minimum pressure, (18) $1.12 * 10^{9}-21.6 * 10^{9} \mathrm{~m}^{3} / \mathrm{s}^{2} \mathrm{PDI}$, and (19) $0.25-3.75 \mathrm{~m}^{2} / \mathrm{s}^{2}$ ACE. Mean values and quantile values (expressed as percentages) were used to calculate fractional 
differences between $\mathrm{LME}_{\text {control }}$ and $\mathrm{LME}_{\text {forced, }}$, and these differences were averaged over all diagnostics for a composite percentage difference. We refer to the mean difference of diagnostics 1-10 as the total "average difference" and the mean difference of diagnostics 11-19 as the total "percentage difference." We also computed these metrics from our downscaled ERA-I data to compare them to the IBTrACS database as a test of our methodology, as described in Sects. 2.2.1 and 2.2.2.

The diagnostics described above were used as test statistics to evaluate whether volcanic eruptions have a measurable effect on hurricane behavior. These diagnostics were selected in order to assess hurricane behavior across a broad range of characteristics. The diagnostics not only quantify hurricane behavior across the temporal and spatial domain, but also assess more fundamental physical characteristics. In addition, the diagnostics can be used with limited data consisting only of time, location, wind speed, and surface pressure. This presents a versatile and efficient approach to capture both mean climatology and structured hurricane behavior.

To determine whether volcanic eruptions affect hurricane statistics, we performed two-sample KS-tests for distributions of each of the diagnostics. The two samples tested for each diagnostic came from downscaled $\mathrm{LME}_{\text {control }}$ and $\mathrm{LME}_{\text {forced }}$ data. Since $\mathrm{LME}_{\text {control }}$ does not include volcanic eruptions, agreement with $\mathrm{LME}_{\text {control }}$ is confirmation of the null hypothesis. We also performed two-sample Anderson-Darling tests to account for long tail effects to which KS-tests are insensitive.

\section{Results}

We first show comparisons in TC tracks between downscaled output from ERA-I and IBTrACS (Fig. 3) as well as between $\mathrm{LME}_{\text {forced }}$ and LME $\mathrm{E}_{\text {control }}$ (Fig. 4). The ERA-I vs. IBTrACS comparison provides a baseline of whether WRF downscales TCs correctly, while the comparison between $\mathrm{LME}_{\text {forced }}$ and $\mathrm{LME}_{\text {control }}$ is focused specifically on the effect of aerosol forcing from volcanic eruptions. There is agreement in the location of TC tracks for both comparisons, however the downscaled ERA-I underestimates TC intensity. This underestimation is likely related to the downscaling resolution of $30 \mathrm{~km}$ and the representation of storms in ERA-I (Lui et al. 2021). There is also a notable lack of TC tracks in the Gulf of Mexico for the downscaled ERA-I compared to the IBTrACS (Fig. 5).

\subsection{ERA-I vs. IBTrACS}

As shown in Table 2, using our suite of diagnostics, we found an overall agreement between ERA-I and IBTrACS

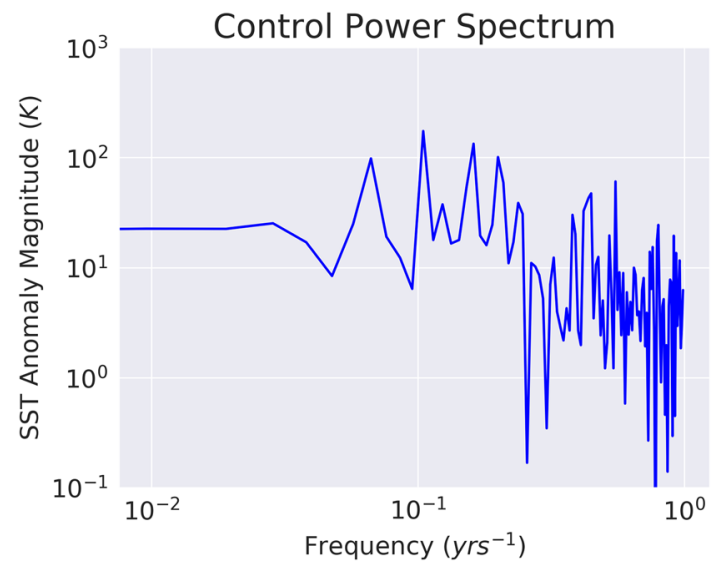

Fig. $3 \mathrm{LME}_{\text {control }}$ SST power spectrum. 100 years of control data is sufficient in capturing low frequency content

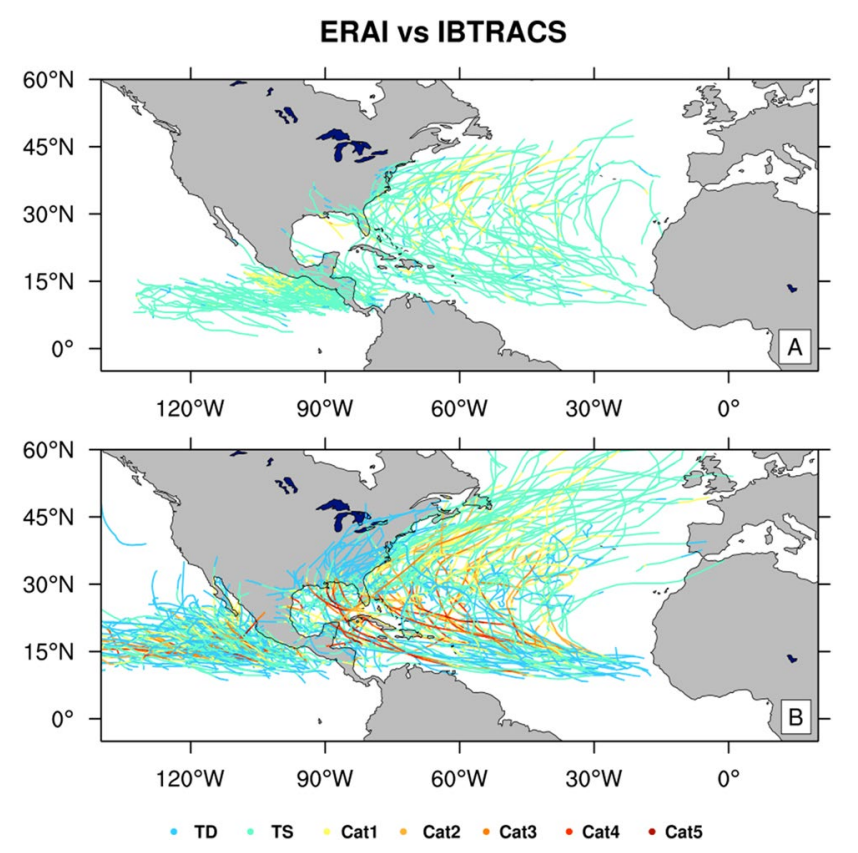

Fig. 4 Downscaled ERA-I hurricane tracks using TSTORMS (A) compared to the IBTrACS database (B) for 1995 through 2005

of $\sim 86.5 \%$, or a composite difference of $\sim 13.5 \%$. 6-hourly ERA-I data downscaled in WRF was compared to IBTrACS for the same time period (1995-2005). Notably, most hurricanes (97\%) from downscaled ERA-I remain below a maximum wind speed of $40 \mathrm{~m} / \mathrm{s}$, whereas $30 \%$ of storms from IBTrACS cross the $40 \mathrm{~m} / \mathrm{s}$ maximum wind speed. Diagnostic distributions for both ERA-I and IBTrACS are shown in Fig. 6. It is worth noting that the truncation of the domain in our ERA-I WRF simulations contributes to the differences in latitude and longitude peaks seen in Fig. 6. For example, according to the IBTrACS database, some storms 


\section{Forced vs Control}
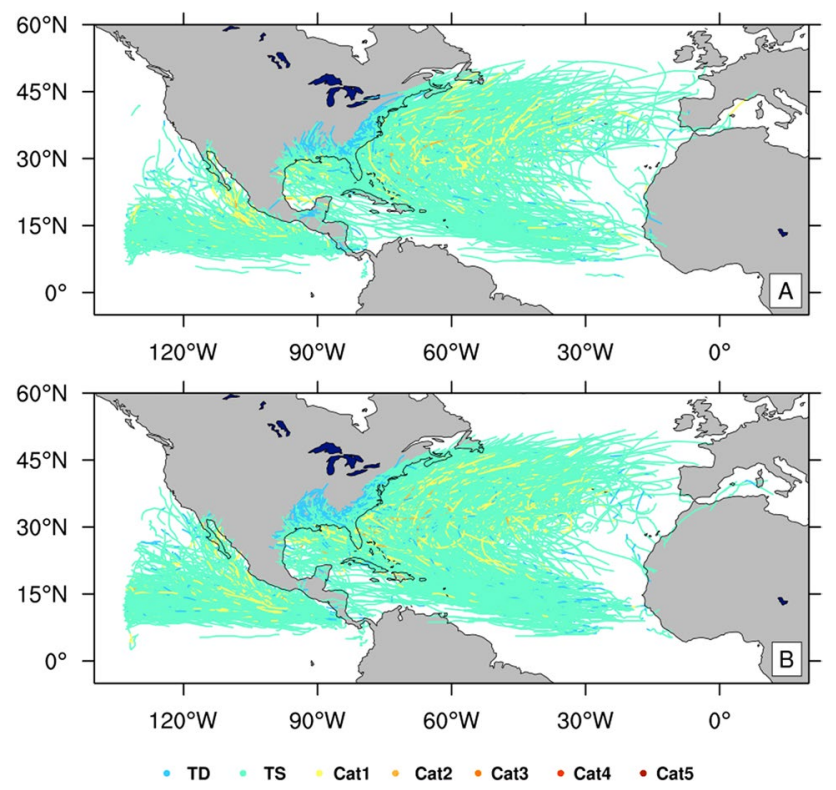

Fig. 5 Downscaled $\mathrm{LME}_{\text {forced }}$ hurricane storm tracks using TSTORMS (A) compared to downscaled $\mathrm{LME}_{\text {control }}$ using TSTORMS (B)

track beyond the WRF domain, while our downscaled ERA-I simulations cut-off where the WRF domain ends. In Hodges et al. (2017), the authors assess how well TCs are represented in reanalysis products. This work used two TC-track matching approaches, referred to as (1) "direct matching" and (2) "objective matching". The authors further used several diagnostics in order to compare reanalysis TC tracks to those found in IBTrACS. The objective matching approach, which employs a tracking algorithm similar to TSTORMS, found an agreement of $\sim 60 \%$ with ERA-I in the Northern Hemisphere. A simple "direct matching" implementation of our own achieved similar agreement. The physics schemes in Sect. 2.2.1 and threshold values in Sect. 2.2.2 were used to satisfy a self-selected $15 \%$ difference threshold imposed between ERA-I and IBTrACS, as quantified by our diagnostics suite.

\subsection{Effect of eruptions on hurricane statistics}

\subsubsection{Average effect of eruptions}

Distributions of the diagnostics for $\mathrm{LME}_{\text {control }}$ and $\mathrm{LME}_{\text {forced }}$, with all 42 eruptions included, are shown in Fig. 7. The same diagnostic comparison for all northern hemisphere eruptions is shown in Fig. 8. All southern hemisphere eruptions are included in the diagnostic comparison shown in Fig. 9. A diagnostic comparison for the top 5 northern hemisphere eruptions is shown in Fig. 10. The top 5 southern hemisphere eruptions are included in Fig. 11. Performing two sample KS-tests and two-sample Anderson-Darling tests on the distributions, along with fractional significance tests on the difference of mean values, shows that the overall effect of all 42 eruptions is consistent with the null hypothesis. That is, the effect of all 42 eruptions is consistent with the natural climate variability seen in $\mathrm{LME}_{\text {control }}$ (Table 3). However, when separating northern and southern hemisphere eruptions, we observe a moderate effect on the frequency, lifetime, and intensity of hurricanes (Tables 4,6 ). The KStests show a maximum difference between the two samples (D-value) and a probability that the two samples are drawn
Table 2 ERA-I vs. IBTrACS statistics for certain variables

\begin{tabular}{lrclll}
\hline Averages & ERA-I & IBTrACS & Percents & ERA-I & IBTrACS \\
\hline Month & 7.65 & 8.24 & May-Nov & 0.88 & 0.99 \\
Yearly num & 31.27 & 34.82 & $0-25 \mathrm{~N}$ & 0.78 & 0.73 \\
Lat & 18.23 & 21.39 & $100-50 \mathrm{~W}$ & 0.65 & 0.44 \\
Lon & -80.72 & -88.38 & $0-40 \mathrm{~m} / \mathrm{s}$ & 0.97 & 0.70 \\
Max wind (m/s) & 30.26 & 34.87 & $1020-980 \mathrm{hPa}$ & 0.81 & 0.62 \\
Min pressure (hPa) & 988.56 & 979.65 & (w) $0-100 \mathrm{~h}$ & 0.94 & 0.91 \\
w-life (hrs) & 45.37 & 44.69 & (p) $0-100 \mathrm{~h}$ & 0.94 & 0.87 \\
p-life (hrs) & 44.02 & 52.53 & & & \\
\hline
\end{tabular}

For the first three columns: month indicates the average time of year for hurricanes (for example, the average hurricane occurred slightly after mid-July for ERA-I), yearly num is the average number of hurricanes, lat is the average latitude of hurricanes, lon is the average longitude, max wind is the average maximum wind speed $(\mathrm{m} / \mathrm{s})$, min pressure is the average minimum pressure $(\mathrm{hPa})$, w-life is the average time in hours from maximum wind speed to average wind speed of a hurricane (represents decay time), p-life is the same as w-life except for minimum pressure to average pressure of the storm. For the second three columns: May-Nov indicates the percentage of TCs that occur between May and November, 0-25 N is the percent of storms that track through this latitude range, $100-50 \mathrm{~W}$ is the percent of storms that track through this range of longitude, $0-40 \mathrm{~m} / \mathrm{s}$ is the percent of storms that are in this wind intensity range, 1020-980 hPa indicates the percent of storms in this pressure range, and (w) and (p) 0-100 h are the percent of storms that decay within $100 \mathrm{~h}$ 

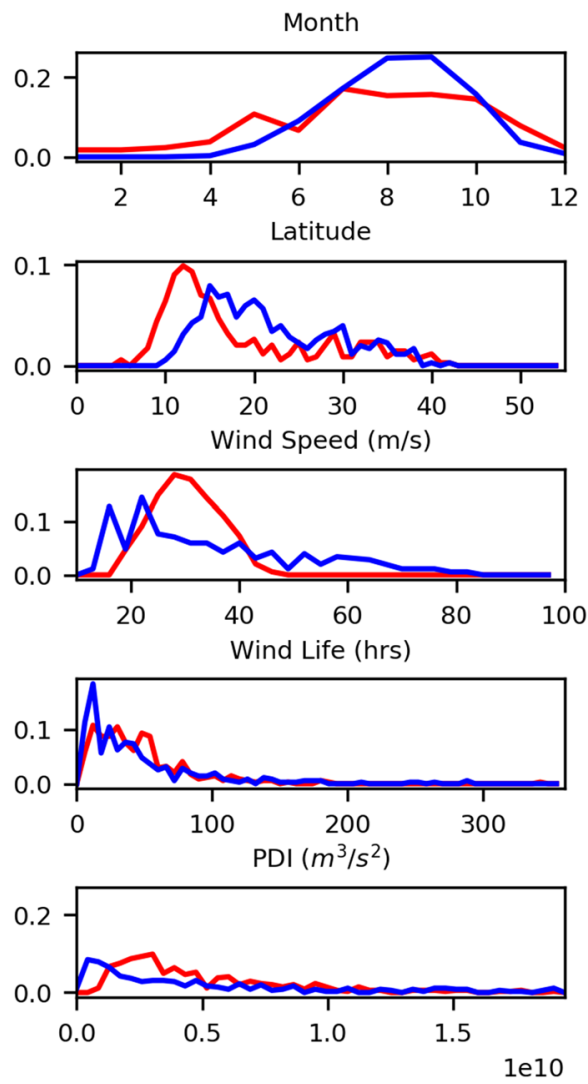

Fig. 6 Average number of storms by time of year (month), year, latitude, longitude, average wind speed, average pressure, lifetime based on decay from maximum wind to average wind, lifetime based on decay from minimum pressure to average pressure, accumulated cyclone energy (ACE), and power dissipation index (PDI), between

from the same distribution (P value). The Anderson-Darling tests give the level at which the null hypothesis can be rejected. For example, in the max wind row of Table 6, an Anderson-Darling test significance value of 0.001 shows that the null hypothesis can be rejected at the $0.1 \%$ level. For all northern hemisphere eruptions (Tables 4,5 ) we can reject the null hypothesis by the Anderson-Darling test for intensity, PDI, and ACE at a maximum level of $13 \%$. For both PDI and ACE we can reject the null hypothesis at around the $2 \%$ level. We see similar results for all southern hemisphere eruptions in Tables 6, 7. The fractional significance tests (Tables 8, 9, 10) show the fraction of TCs in $\mathrm{LME}_{\text {control }}$ which exceed the $\mathrm{LME}_{\text {forced }}$ mean. For example, in the max wind row of Table 8, 53.2\% of the TCs in $\mathrm{LME}_{\text {control }}$ had stronger maximum wind speed than the mean maximum
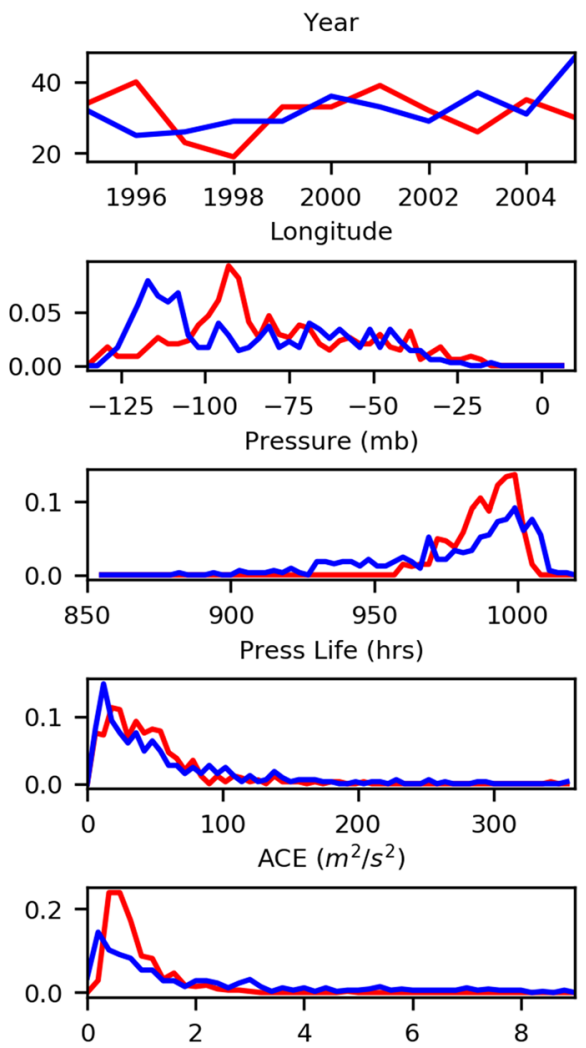

downscaled ERA-I and IBTrACS for 1995 through 2005. Bin widths are $1^{\circ}, 3^{\circ}, 1 \mathrm{~m} / \mathrm{s}, 1 \mathrm{mb}$ for latitude, $6 \mathrm{~h}$, and $6 \mathrm{~h}$ for longitude, wind speed, pressure, wind life, and pressure life respectively. Distributions are normalized by the total number of storms

wind speed of TCs in $\mathrm{LME}_{\text {forced }}$. For all northern hemisphere eruptions, we see in Table 9 that TCs have a shorter lifetime, lower maximum intensity, and lower latitude than $55-70 \%$ of TCs in $\mathrm{LME}_{\text {control. }}$. We also find that TCs following northern hemisphere eruptions have a lower PDI and ACE than 65\% of TCs in the control. In contrast, we observe the opposite effect with southern hemisphere eruptions. As shown in Table 10, TCs following southern hemisphere eruptions have longer lifetimes, larger maximum intensity, increased latitudes, and larger PDI/ACE than nearly $60 \%$ of TCs in the control.

We also calculated Pearson correlation coefficients on eruption strength and diagnostic changes. To determine the significance of these correlation coefficients, we calculated the $90 \%, 85 \%$, and $80 \%$ confidence intervals. If 


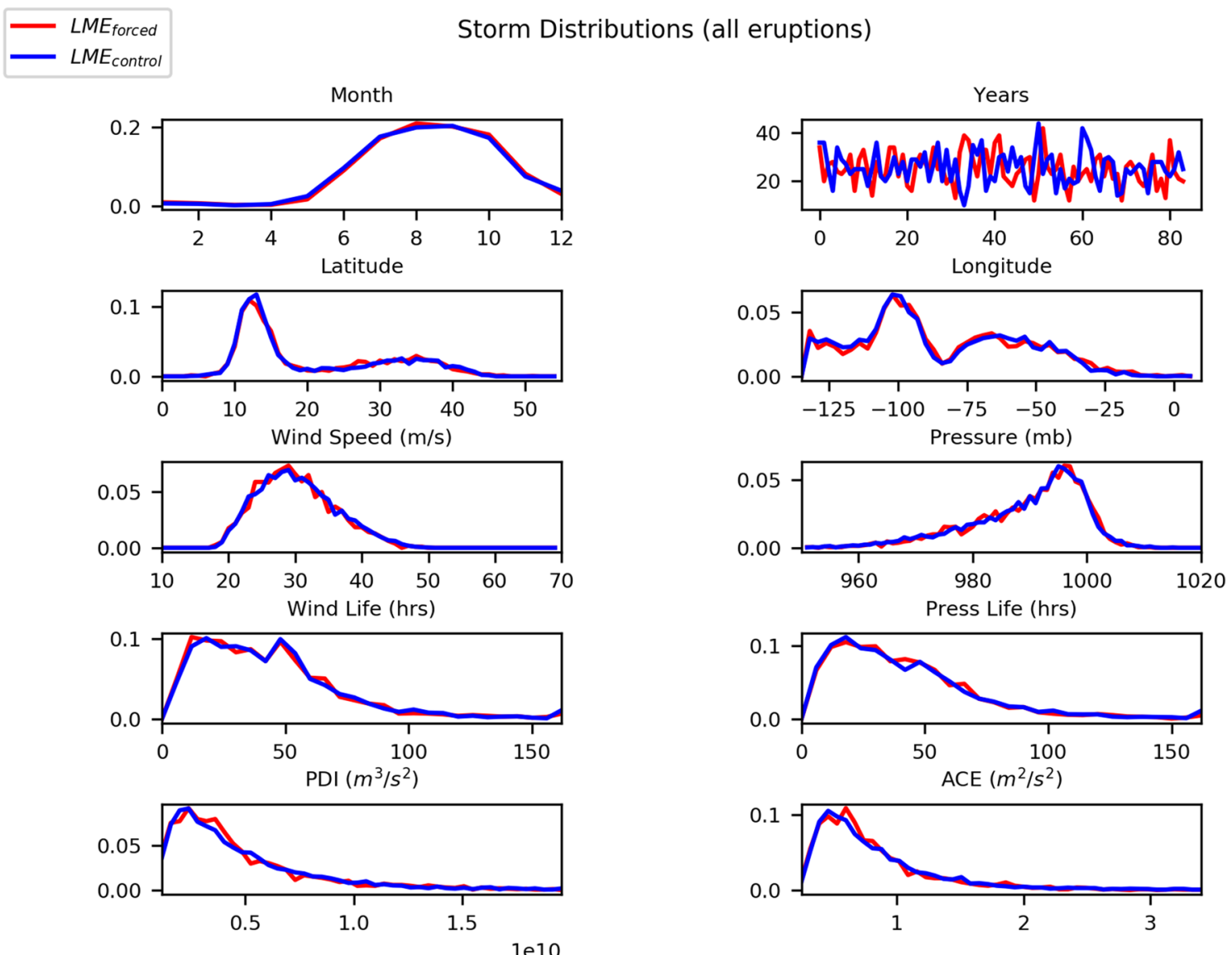

Fig. 7 Same as Fig. 6 except for a comparison between $\mathrm{LME}_{\text {forced }}$ and $\mathrm{LME}_{\text {control }}$ for all eruptions in both hemispheres

the confidence interval for a particular diagnostic (e.g., maximum wind speed) does not include zero correlation we can say with at least $90 \%, 85 \%$, or $80 \%$ confidence that there is a correlation between eruption strength and that particular diagnostic. These confidence intervals are affected by the number of eruptions in our analysis. The correlation coefficients for all eruptions in both hemispheres are listed in Table 11. Here, we see with at least $80 \%$ confidence that there is a correlation between eruption strength and reduction in yearly hurricane number, intensity, and lifetime. The correlation coefficients for all northern hemisphere eruptions are shown in Table 12 . Again we see with at least $80 \%$ confidence that there is a correlation between eruption strength and reduction in yearly hurricane number, maximum wind speed, and lifetime. The correlation coefficients for all southern hemisphere eruptions are shown in Table 13. Here we again see with at least $80 \%$ confidence there is a correlation between eruption strength and reduction in intensity. We also see with at least $80 \%$ confidence a correlation between eruption strength and storms occurring earlier in the year. However, for the southern hemisphere we do not see the same correlation between eruption strength and reduction in yearly number or lifetime. For the southern hemisphere we see with at least $80 \%$ confidence a correlation between eruption strength and storm occurring later in the year. The opposite effect is seen for northern hemisphere eruptions. 


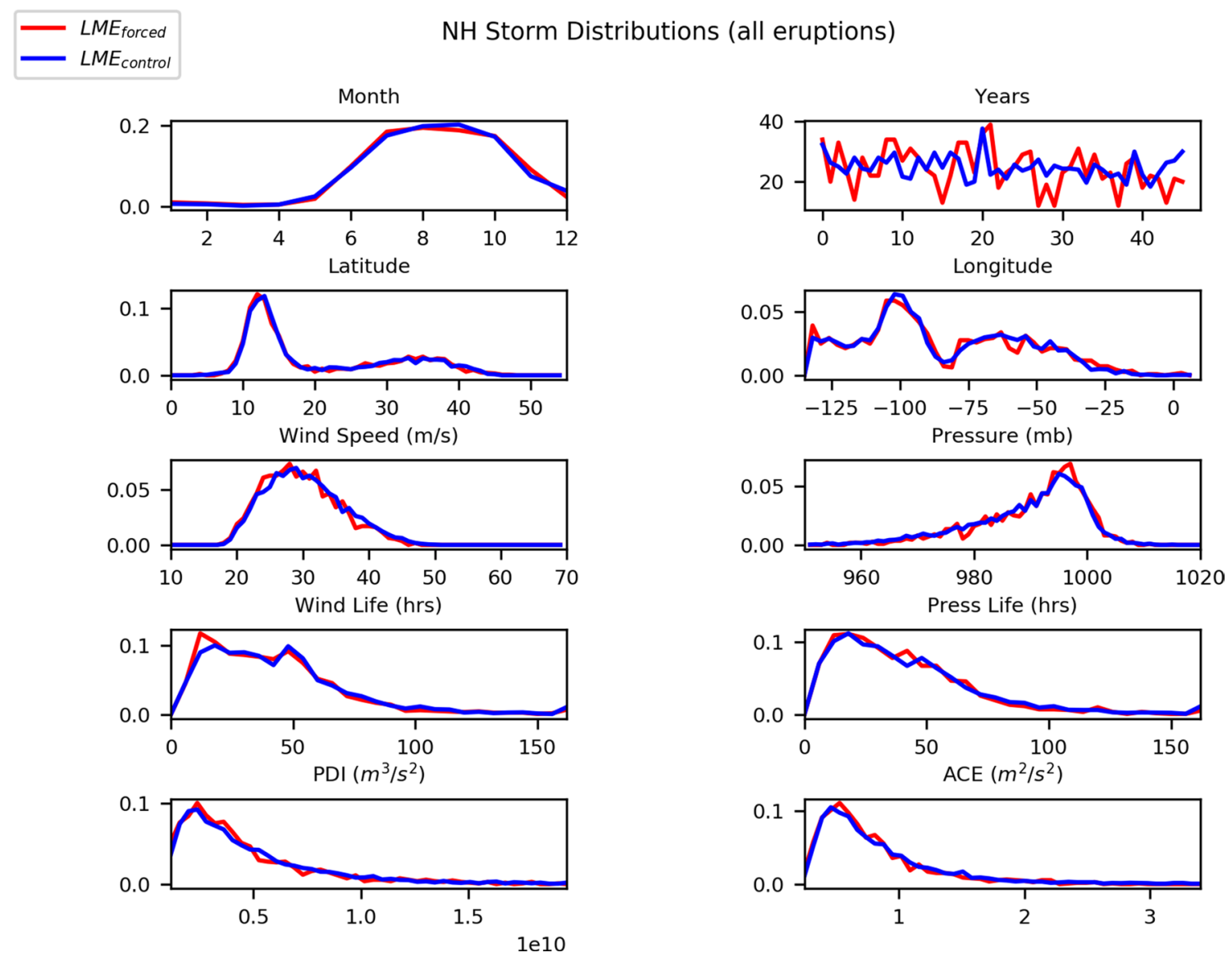

Fig. 8 Same as Fig. 6 except for a comparison between $\mathrm{LME}_{\text {forced }}$ and $\mathrm{LME}_{\text {control }}$ for all eruptions in the northern hemisphere

\subsubsection{Effect of strongest eruptions}

Distributions of diagnostics with only the 5 strongest northern hemisphere eruptions are shown in Fig. 10. The same diagnostics for the 5 strongest southern hemisphere eruptions are shown in Fig. 11. The results of running KS-tests and Anderson-Darling tests for the 5 strongest northern hemisphere eruptions are shown in Table 5. The results for the 5 strongest southern hemisphere eruptions are shown in Table 7. For the 5 largest eruptions, in both the northern and southern hemispheres we can reject the null hypothesis by the Anderson-Darling test for nearly every diagnostic at a maximum level of $1 \%$. The fractional significance tests on the strongest northern hemisphere and southern hemisphere eruptions are in Tables 9 and 10, respectively. We see in Table 9 that for the 5 strongest northern hemisphere eruptions $70-80 \%$ of TCs have a lower maximum intensity, shorter lifetime, and are found at a lower latitude than
TCs in $\mathrm{LME}_{\text {control. }}$. Following the strongest eruption (1258) nearly $80-90 \%$ of TCs exhibit this reduced lifetime, maximum intensity, and latitude. We see in Table 10 that for the 5 strongest southern hemisphere eruptions there is the opposite effect to that of northern hemisphere eruptions. In this case nearly $60 \%$ of TCs following eruptions have an increased lifetime, maximum intensity, and latitude. However, we still observe a similar reduction in power dissipation index and accumulated cyclone energy.

\section{Discussion and conclusion}

In this work we have explored the effect of volcanic eruptions in the past millennium on hurricane climatology. To do this we first validated our approach of downscaling CESM data with WRF by comparing results of ERA-I downscaling with IBTrACS data. ERA-I downscaling was only able to 


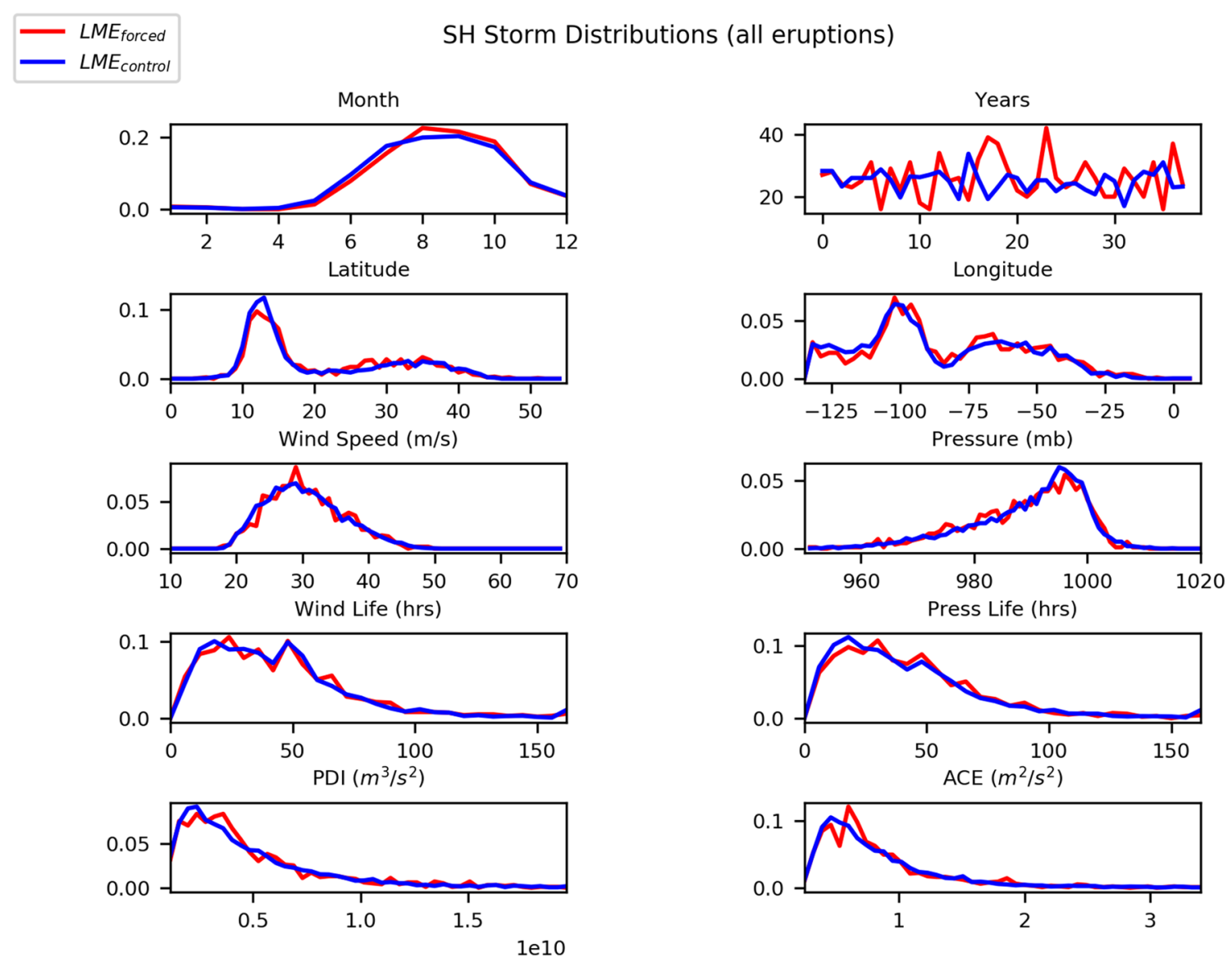

Fig. 9 Same as Fig. 6 except for a comparison between $\mathrm{LME}_{\text {forced }}$ and $\mathrm{LME}_{\text {control }}$ for all eruptions in the southern hemisphere

partially reproduce IBTrACS observations however, underestimating observational intensities. On the other hand, frequency, limetime, and location were faithfully reproduced in the ERA-I downscaling. The underestimation of intensity could limit measurable effects in our intensity-based diagnostics. We also performed a parameter search for our cyclone tracking algorithm in order to achieve high accuracy. We then compared the results of downscaling our control data from CESM with forced data from CESM, where we focused on the years in the forced data with volcanic eruptions.

Our results suggest that the overall effect of all eruptions on hurricane statistics is small and not significant as compared to the control simulation (i.e., the null hypothesis). However, we see a moderate reduction in frequency, lifetime, and maximum intensity for hurricanes following northern hemisphere eruptions and the opposite for southern hemisphere eruptions. Sufficiently strong northern hemisphere eruptions do result in lower annual hurricane count, reduced intensity, and shorter lifetimes, significant at the $70-80^{\text {th }}$ percentile. This evidence is in the form of KS, Anderson-Darling, and fractional significance tests on diagnostic distributions, as well as correlations between strength and changes in the mean values of these diagnostics. The moderate increase in North Atlantic TC activity following southern hemisphere eruptions substantiates previous research suggesting moisture convergence increases in the hemisphere opposite of a volcanic eruption (e.g., Haywood et al. 2013). 


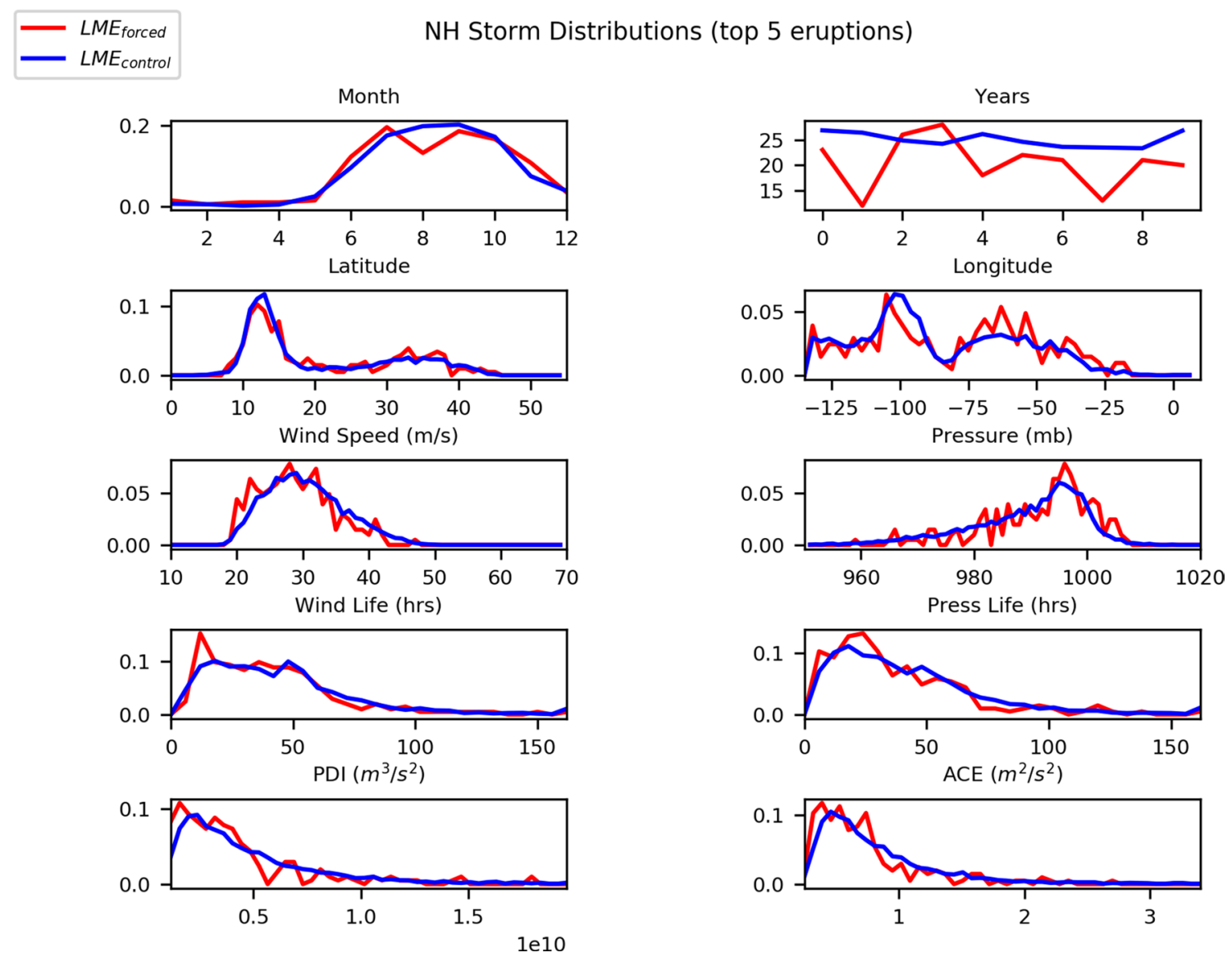

Fig. 10 Same as Fig. 6 except for only the five strongest eruptions in the northern hemisphere

Comparing the downscaled ERA-I results to hurricane tracks and intensities from IBTrACS allowed us to evaluate the efficacy of our approach. Due to the inherently chaotic nature of hurricane genesis, exact agreement between ERA-I and IBTrACS was not expected, especially given the coarse $30 \mathrm{~km}$ resolution of our downscaled simulations. Assessing our approach was the primary objective in comparing ERA-I with IBTrACS. We expected ERA-I to capture the observational record for mean climate and to provide good agreement between downscaled results and overall hurricane statistics seen in IBTrACS. We avoided using metrics like PI, since caution is urged in using PI to draw strong conclusions about tropical cyclone projections as it fails to capture features seen in high-resolution climate models (Wehner et al. 2015). Dynamical downscaling provides far greater detail in both the spatial and temporal domain (Emanuel 2013). This is evident in Figs. 4 and 5 and the extensive suite of diagnostics used to analyze downscaled results.

The results in this study have significant implications for hurricane development in a potential future climate under an SAI regime. Although we analyzed the effects of an increase in stratospheric aerosols from volcanic eruptions, the results are relevant to what may occur under an SAI 

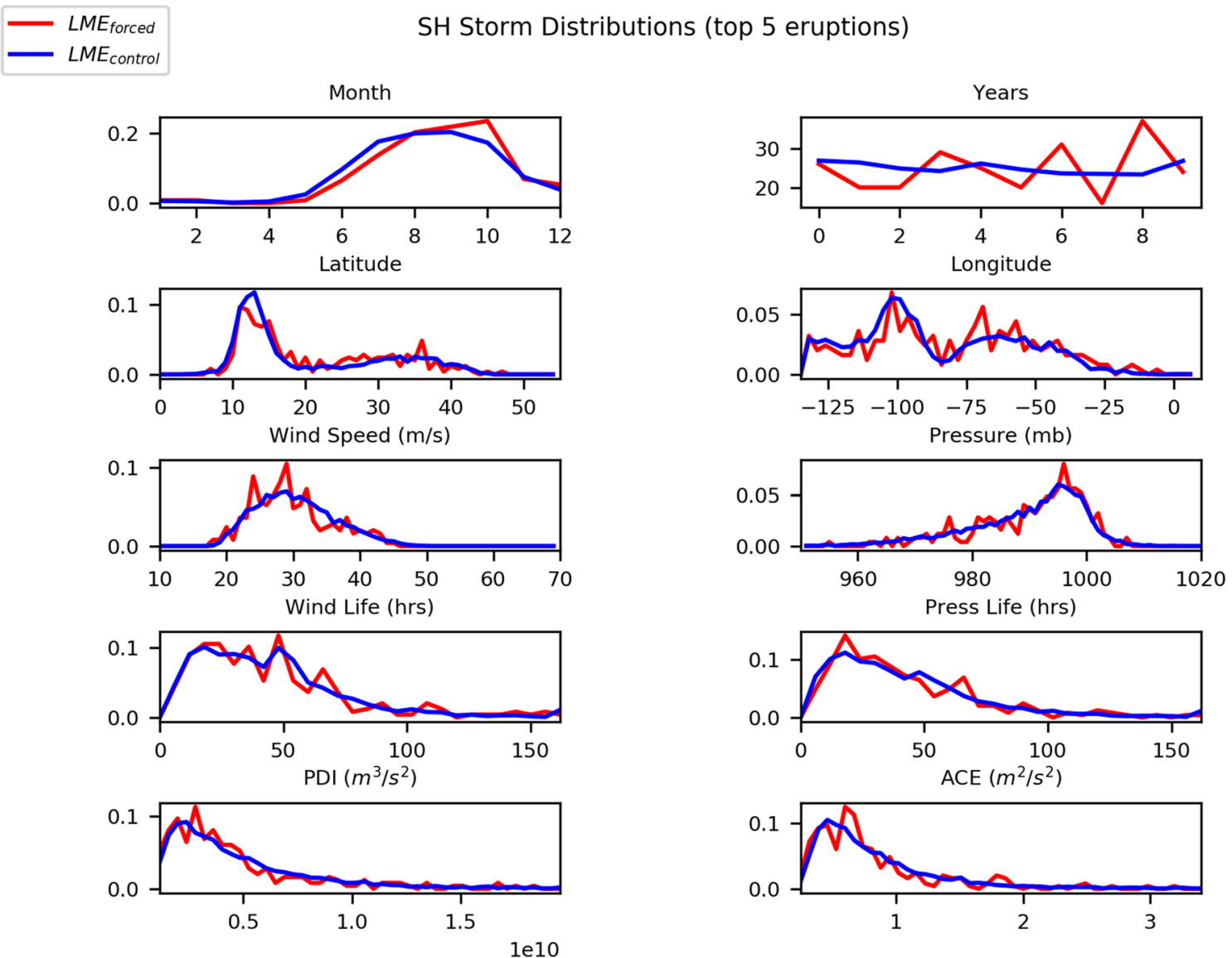

Fig. 11 Same as Fig. 6 except for only the five strongest eruptions in the southern hemisphere

Table 3 KS-tests show a maximum difference between the two samples (D value) and a probability that the two samples are drawn from the same distribution

\begin{tabular}{llll}
\hline & $\begin{array}{l}\text { All eruptions } \\
\text { D-value }\end{array}$ & $\begin{array}{l}\text { All eruptions } \\
\text { P value }\end{array}$ & $\begin{array}{l}\text { All eruptions } \\
\text { significance }\end{array}$ \\
\hline Month & 0.0 & 1.0 & 0.25 \\
Yearly num & 0.016 & 1.0 & 0.25 \\
Lat & 0.01 & 1.0 & 0.25 \\
Lon & 0.002 & 1.0 & 0.25 \\
Max wind (m/s) & 0.01 & 1.0 & 0.25 \\
Min pressure (hPa) & 0.006 & 1.0 & 0.25 \\
w-life $(\mathrm{hrs})$ & 0.004 & 1.0 & 0.25 \\
p-life $(\mathrm{hrs})$ & 0.0 & 1.0 & 0.25 \\
PDI $\left(\mathrm{m}^{3} / \mathrm{s}^{2}\right)$ & 0.01 & 1.0 & 0.2 \\
ACE $\left(\mathrm{m}^{2} / \mathrm{s}^{2}\right)$ & 0.01 & 1.0 & 0.25 \\
\hline
\end{tabular}

Anderson-Darling tests give the level (Significance) at which the null hypothesis can be rejected. The maximum level given by the Anderson-Darling tests is 0.25. (Both Hemispheres)
Table 4 KS-tests (D- and P-values) and Anderson-Darling tests (Significance) for all eruptions. (Northern Hemisphere)

\begin{tabular}{llll}
\hline & $\begin{array}{l}\text { All eruptions } \\
\text { D-value }\end{array}$ & $\begin{array}{l}\text { All eruptions } \\
\text { P-value }\end{array}$ & $\begin{array}{l}\text { All eruptions } \\
\text { significance }\end{array}$ \\
\hline Month & 0.0 & 1.0 & 0.25 \\
Yearly num & 0.016 & 1.0 & 0.0425 \\
$\quad$ Lat & 0.014 & 1.0 & 0.25 \\
Lon & 0.016 & 1.0 & 0.25 \\
Max wind (m/s) & 0.02 & 1.0 & 0.128 \\
Min pressure $(\mathrm{hPa})$ & 0.026 & 1.0 & 0.068 \\
w-life $(\mathrm{hrs})$ & 0.008 & 1.0 & 0.25 \\
p-life $(\mathrm{hrs})$ & 0.008 & 1.0 & 0.25 \\
PDI $\left(\mathrm{m}^{3} / \mathrm{s}^{2}\right)$ & 0.026 & 1.0 & 0.0175 \\
ACE $\left(\mathrm{m}^{2} / \mathrm{s}^{2}\right)$ & 0.016 & 1.0 & 0.027 \\
\hline
\end{tabular}


Table 5 KS-tests (D- and P values) and Anderson-Darling tests (significance) for 5 strongest eruptions (Northern Hemisphere)

\begin{tabular}{llll}
\hline & $\begin{array}{l}\text { 5 Strongest } \\
\text { eruptions D } \\
\text { value }\end{array}$ & $\begin{array}{l}\text { 5 Strongest } \\
\text { eruptions P } \\
\text { value }\end{array}$ & $\begin{array}{l}\text { 5 Eruptions } \\
\text { significance }\end{array}$ \\
\hline Month & 0.004 & 1.0 & 0.25 \\
Yearly num & 0.048 & 0.6 & 0.001 \\
Lat & 0.05 & 0.55 & 0.001 \\
Lon & 0.048 & 0.6 & 0.001 \\
Max wind (m/s) & 0.036 & 0.9 & 0.001 \\
Min pressure $(\mathrm{hPa})$ & 0.062 & 0.28 & 0.001 \\
w-life $(\mathrm{hrs})$ & 0.026 & 1.0 & 0.0069 \\
$\mathrm{p}-$ life $(\mathrm{hrs})$ & 0.024 & 1.0 & 0.0125 \\
PDI $\left(\mathrm{m}^{3} / \mathrm{s}^{2}\right)$ & 0.05 & 0.55 & 0.001 \\
ACE $\left(\mathrm{m}^{2} / \mathrm{s}^{2}\right)$ & 0.044 & 0.71 & 0.001 \\
\hline
\end{tabular}

Table 6 KS-tests (D- and P values) and Anderson-Darling tests (significance) for all eruptions (southern hemisphere)

\begin{tabular}{llll}
\hline & $\begin{array}{l}\text { All eruptions } \\
\text { D value }\end{array}$ & $\begin{array}{l}\text { All eruptions } \\
\text { P value }\end{array}$ & $\begin{array}{l}\text { All eruptions } \\
\text { significance }\end{array}$ \\
\hline Month & 0.002 & 1.0 & 0.25 \\
Yearly num & 0.01 & 1.0 & 0.0059 \\
Lat & 0.022 & 1.0 & 0.119 \\
Lon & 0.01 & 1.0 & 0.25 \\
Max wind $(\mathrm{m} / \mathrm{s})$ & 0.016 & 1.0 & 0.25 \\
Min pressure $(\mathrm{hPa})$ & 0.026 & 1.0 & 0.068 \\
w-life $(\mathrm{hrs})$ & 0.008 & 1.0 & 0.25 \\
p-life $(\mathrm{hrs})$ & 0.006 & 1.0 & 0.25 \\
PDI $\left(\mathrm{m}^{3} / \mathrm{s}^{2}\right)$ & 0.024 & 1.0 & 0.03 \\
ACE $\left(\mathrm{m}^{2} / \mathrm{s}^{2}\right)$ & 0.022 & 1.0 & 0.015 \\
\hline
\end{tabular}

Table 7 KS-tests (D- and P values) and Anderson-Darling tests (Significance) for 5 strongest eruptions (Southern Hemisphere)

\begin{tabular}{llll}
\hline & $\begin{array}{l}\text { 5 Strongest } \\
\text { eruptions D } \\
\text { value }\end{array}$ & $\begin{array}{l}\text { 5 Strongest } \\
\text { eruptions P } \\
\text { value }\end{array}$ & $\begin{array}{l}\text { 5 Strongest erup- } \\
\text { tions significance }\end{array}$ \\
\hline Month & 0.006 & 1.0 & 0.25 \\
Yearly num & 0.048 & 0.6 & 0.001 \\
Lat & 0.05 & 0.55 & 0.001 \\
Lon & 0.044 & 0.71 & 0.001 \\
Max wind (m/s) & 0.034 & 0.93 & 0.00129 \\
Min pressure & 0.06 & 0.32 & 0.001 \\
$\quad(\mathrm{hPa})$ & 0.026 & 1.0 & 0.0069 \\
w-life $(\mathrm{hrs})$ & 0.02 & 1.0 & 0.055 \\
$\mathrm{p}-$ life $(\mathrm{hrs})$ & 0.052 & 0.5 & 0.001 \\
PDI $\left(\mathrm{m}^{3} / \mathrm{s}^{2}\right)$ & 0.042 & 0.76 & 0.001 \\
ACE $\left(\mathrm{m}^{2} / \mathrm{s}^{2}\right)$ & & & \\
\hline
\end{tabular}

Table 8 Fractional significance tests for all eruptions

\begin{tabular}{ll}
\hline & All eruptions \\
\hline Month & 0.513 \\
Yearly num & 0.435 \\
Lat & 0.494 \\
Lon & 0.435 \\
Max wind (m/s) & 0.532 \\
Min pressure $(\mathrm{hPa})$ & 0.494 \\
w-life $(\mathrm{hrs})$ & 0.565 \\
p-life $(\mathrm{hrs})$ & 0.506 \\
PDI $\left(\mathrm{m}^{3} / \mathrm{s}^{2}\right)$ & 0.552 \\
ACE $\left(\mathrm{m}^{2} / \mathrm{s}^{2}\right)$ & 0.558
\end{tabular}

The values indicate the fraction of TCs in $\mathrm{LME}_{\text {control }}$ which exceed the $\mathrm{LME}_{\text {forced }}$ mean, for a given variable (both hemispheres)

regime. Although analyses of impacts were once limited by historical observation and coarser resolution, we were able to evaluate the direct influence of many volcanic eruptions on individual hurricanes. For example, northern hemisphere eruptions in the downscaled $\mathrm{LME}_{\text {forced }}$ experiment produced a slight reduction in hurricane frequency, intensity, and lifetime. These impacts could be similarly felt if SAI is designed to mimic the injection from the northern hemisphere eruptions, removing some uncertainty associated with regional changes in tropical cyclone development for the Northern Atlantic Ocean. According to our results, hurricanes would likely decrease in frequency, lifetime, and intensity under a relatively strong SAI regime with aerosol injection in the northern hemisphere.

Although our results show moderate correlation between eruption strength and certain diagnostic measures, it is not necessarily true that stronger eruptions have a larger effect on hurricane statistics. Additionally, research has shown large uncertainties in volcanic reconstructions and seasonality of volcanic eruptions (Schmidt et al. 2012; Stevenson et al. 2017; Raible et al. 2016), which presents a direction for further investigation. In this vein, one could look at an ensemble of higher resolution GCM simulations on one or two of the strongest volcanic eruptions. This eruption profile could be simulated both in the climate conditions during the historical eruption as well as under future climate change conditions. An ensemble average of simulations with perturbed initial conditions will allow us to home in on the sole effect of aerosol forcing. This will also allow us to explore the question of whether downscaling introduced any unknown biases. An ensemble under future climate change conditions will allow us to explore the interplay of large aerosol forcing and strong anthropogenic forcing. 
Table 9 Fractional significance tests for all eruptions, the 10 strongest eruptions, the 5 largest eruptions, and the largest eruption (1258)

\begin{tabular}{lllll}
\hline & All eruptions & $\begin{array}{l}\text { 10 Strongest erup- } \\
\text { tions }\end{array}$ & $\begin{array}{l}\text { 5 Strongest erup- } \\
\text { tions }\end{array}$ & 1258 Eruption \\
\hline Month & 0.597 & 0.552 & 0.565 & 0.623 \\
Yearly num & 0.539 & 0.539 & 0.435 & 0.753 \\
Lat & 0.584 & 0.584 & 0.786 & 0.818 \\
Lon & 0.494 & 0.435 & 0.708 & 0.656 \\
max wind (m/s) & 0.662 & 0.721 & 0.766 & 0.877 \\
min pressure $(\mathrm{hPa})$ & 0.357 & 0.383 & 0.364 & 0.175 \\
w-life $(\mathrm{hrs})$ & 0.662 & 0.675 & 0.721 & 0.63 \\
p-life $(\mathrm{hrs})$ & 0.63 & 0.63 & 0.747 & 0.766 \\
PDI $\left(\mathrm{m}^{3} / \mathrm{s}^{2}\right)$ & 0.656 & 0.714 & 0.799 & 0.89 \\
ACE $\left(\mathrm{m}^{2} / \mathrm{s}^{2}\right)$ & 0.656 & 0.721 & 0.818 & 0.935 \\
\hline
\end{tabular}

The values indicate the fraction of TCs in $\mathrm{LME}_{\text {control }}$ which exceed the $\mathrm{LME}_{\text {forced }}$ mean, for a given variable (northern hemisphere)

\begin{tabular}{lllll}
\hline & All eruptions & $\begin{array}{l}\text { 10 Strongest erup- } \\
\text { tions }\end{array}$ & $\begin{array}{l}\text { 5 Strongest erup- } \\
\text { tions }\end{array}$ & 1452 Eruption \\
\hline Month & 0.422 & 0.292 & 0.377 & 0.156 \\
Yearly num & 0.39 & 0.435 & 0.325 & 0.169 \\
Lat & 0.403 & 0.338 & 0.396 & 0.649 \\
Lon & 0.364 & 0.318 & 0.526 & 0.643 \\
Max wind (m/s) & 0.429 & 0.416 & 0.331 & 0.461 \\
Min pressure (hPa) & 0.643 & 0.617 & 0.649 & 0.675 \\
w-life (hrs) & 0.422 & 0.409 & 0.318 & 0.305 \\
p-life $(\mathrm{hrs})$ & 0.377 & 0.409 & 0.37 & 0.357 \\
PDI $\left(\mathrm{m}^{3} / \mathrm{s}^{2}\right)$ & 0.448 & 0.565 & 0.617 & 0.669 \\
ACE $\left(\mathrm{m}^{2} / \mathrm{s}^{2}\right)$ & 0.455 & 0.578 & 0.61 & 0.721 \\
\hline
\end{tabular}

The values indicate the fraction of TCs in $\mathrm{LME}_{\text {control }}$ which exceed the $\mathrm{LME}_{\text {forced }}$ mean, for a given variable (southern hemisphere)
Table 10 Fractional significance tests for all eruptions, the 10 strongest eruptions, the 5 largest eruptions, and the largest eruption (1452)

Table 11 Correlations between eruption strength and diagnostics for all eruptions in both hemispheres

\begin{tabular}{lllll}
\hline & All eruptions & $90 \%$ confidence interval & $85 \%$ confidence interval & $80 \%$ confidence interval \\
\hline Month & -0.129 & $-0.3747,0.1337$ & $-0.3455,0.1005$ & $-0.323,0.0754$ \\
Yearly num & -0.2088 & $-0.4431,0.0522$ & $-0.4157,0.0187$ & $-0.3946,-0.0066$ \\
Lat & 0.0176 & $-0.2417,0.2746$ & $-0.2098,0.2432$ & $-0.1855,0.2193$ \\
Lon & 0.1959 & $-0.0657,0.4323$ & $-0.0321,0.4045$ & $-0.0068,0.3832$ \\
Max wind (m/s) & -0.3176 & $-0.5322,-0.0647$ & $0.5077,-0.0981$ & $-0.4886,-0.1231$ \\
Min pressure (hPa) & 0.2951 & $0.0399,0.5142$ & $0.0734,0.489$ & $0.0985,0.4695$ \\
w-life (hrs) & -0.0875 & $-0.3381,0.1747$ & $-0.308,0.1419$ & $-0.2849,0.117$ \\
p-life $(\mathrm{hrs})$ & -0.2927 & $-0.5122,-0.0373$ & $-0.487,-0.0708$ & $-0.4674,-0.0959$ \\
PDI $\left(\mathrm{m}^{3} / \mathrm{s}^{2}\right)$ & -0.3577 & $-0.5633,-0.1104$ & $-0.5405,-0.1427$ & $-0.5223,-0.1674$ \\
ACE $\left(\mathrm{m}^{2} / \mathrm{s}^{2}\right)$ & -0.3876 & $-0.5865,-0.1445$ & $-0.5646,-0.1765$ & $-0.5471,-0.2009$ \\
\hline
\end{tabular}


Table 12 Correlations between eruption strength and diagnostics for all eruptions in the Northern Hemisphere

\begin{tabular}{lclll}
\hline & All eruptions & $90 \%$ confidence interval & $85 \%$ confidence interval & $80 \%$ confidence interval \\
\hline Month & -0.4093 & $-0.6655,-0.0668$ & $-0.6392,-0.1123$ & $0.6178,-0.147$ \\
Yearly num & -0.3267 & $-0.6088,0.0287$ & $-0.5791,-0.0171$ & $-0.5551,-0.0524$ \\
Lat & 0.0669 & $-0.2921,0.4094$ & $-0.2496,0.3705$ & $-0.2162,0.3396$ \\
Lon & 0.2673 & $-0.0936,0.5661$ & $-0.048,0.5342$ & $-0.0127,0.5084$ \\
Max wind (m/s) & -0.293 & $-0.5848,0.0659$ & $-0.5538,0.0201$ & $-0.5288,-0.0152$ \\
Min pressure (hPa) & 0.2447 & $-0.1175,0.5495$ & $-0.0721,0.5167$ & $-0.0369,0.4903$ \\
w-life $(\mathrm{hrs})$ & -0.0942 & $-0.432,0.2667$ & $-0.394,0.2237$ & $-0.3637,0.1899$ \\
p-life $(\mathrm{hrs})$ & -0.3255 & $-0.6079,0.03$ & $-0.5782,-0.0158$ & $-0.5542,-0.0511$ \\
PDI $\left(\mathrm{m}^{3} / \mathrm{s}^{2}\right)$ & -0.3592 & $-0.6314,-0.0081$ & $-0.6031,-0.0539$ & $-0.5801,-0.0891$ \\
ACE $\left(\mathrm{m}^{2} / \mathrm{s}^{2}\right)$ & -0.4239 & $-0.6752,-0.0844$ & $-0.6495,-0.1297$ & $-0.6286,-0.1643$ \\
\hline
\end{tabular}

Table 13 Correlations between eruption strength and diagnostics for all eruptions in the Southern Hemisphere

\begin{tabular}{lclll}
\hline & All eruptions & $90 \%$ confidence interval & $85 \%$ confidence interval & $80 \%$ confidence interval \\
\hline Month & 0.4059 & $0.0194,0.6868$ & $0.0706,0.6588$ & $0.1097,0.6359$ \\
Yearly num & 0.0702 & $-0.3283,0.4475$ & $-0.2818,0.4056$ & $-0.2451,0.3721$ \\
Lat & -0.0491 & $-0.4304,0.3471$ & $-0.3877,0.3012$ & $-0.3537,0.2649$ \\
Lon & 0.095 & $-0.3059,0.4672$ & $-0.2587,0.4262$ & $-0.2215,0.3934$ \\
Max wind (m/s) & -0.3469 & $-0.6488,0.0493$ & $-0.6181,-0.0019$ & $-0.5931,-0.0414$ \\
Min pressure (hPa) & 0.3676 & $-0.0256,0.6623$ & $0.0256,0.6325$ & $0.0651,0.6083$ \\
w-life $(\mathrm{hrs})$ & 0.021 & $-0.3716,0.4072$ & $-0.3266,0.3636$ & $-0.2909,0.3288$ \\
p-life $(\mathrm{hrs})$ & -0.1701 & $-0.5249,0.235$ & $-0.4867,0.186$ & $-0.456,0.1476$ \\
PDI $\left(\mathrm{m}^{3} / \mathrm{s}^{2}\right)$ & -0.3782 & $-0.6692,0.0133$ & $-0.6399,-0.0379$ & $-0.616,-0.0773$ \\
ACE $\left(\mathrm{m}^{2} / \mathrm{s}^{2}\right)$ & -0.3546 & $-0.6538,0.0405$ & $-0.6235,-0.0107$ & $-0.5987,-0.0502$ \\
\hline
\end{tabular}

Acknowledgements We are grateful for the early assistance we received from Dr. Bette Otto-Bliesner in setting up the original LME control as well as to Yu Izuka for his initial work on this project. Additionally, we thank the reviewers for numerous helpful comments which significantly improved the paper. We would like to acknowledge highperformance computing support from Cheyenne (https://doi.org/10. 5065/D6RX99HX) provided by NCAR's Computational and Information Systems Laboratory, sponsored by the National Science Foundation. Both Dr. Benton and Dr. Ault were partially supported by NSF Grants AGS 1602564 and AGS 1751535. The authors declare no conflicts of interest with this publication.

Open Access This article is licensed under a Creative Commons Attribution 4.0 International License, which permits use, sharing, adaptation, distribution and reproduction in any medium or format, as long as you give appropriate credit to the original author(s) and the source, provide a link to the Creative Commons licence, and indicate if changes were made. The images or other third party material in this article are included in the article's Creative Commons licence, unless indicated otherwise in a credit line to the material. If material is not included in the article's Creative Commons licence and your intended use is not permitted by statutory regulation or exceeds the permitted use, you will need to obtain permission directly from the copyright holder. To view a copy of this licence, visit http://creativecommons.org/licenses/by/4.0/.

\section{References}

Bister M, Emanuel KA (2002) Low frequency variability of tropical cyclone potential intensity 1 . Interannual to interdecadal variability. J Geophys Res Atmos 107(D24):ACL 26-1-ACL 26-15. https://doi.org/10.1029/2001JD000776

Bluth GJS, Doiron SD, Schnetzler CC, Krueger AJ, Walter LS (1992) Global tracking of the SO2 clouds from the June 1991 Mount Pinatubo eruptions. Geophys Res Lett 19:151-154

Bruyere CL, Monaghan AJ, Steinhoff DF, Yates D (2015) Bias-corrected CMIP5 CESM data in WRF/MPAS intermediate file format. https://doi.org/10.5065/D6445JJ7

Caldeira K, Wood L (2008) Global and Arctic climate engineering: numerical model studies. Philos Trans R Soc A Math Phys Eng Sci 366(1882):4039-4056. https://doi.org/10.1098/rsta.2008.0132

Camargo SJ, Polvani LM (2019) Little evidence of reduced global tropical cyclone activity following recent volcanic eruptions. Npj Clim Atmos Sci 2(1):14. https://doi.org/10.1038/s41612-019-0070-z

Colose CM, LeGrande AN, Vuille M (2016) Hemispherically asymmetric volcanic forcing of tropical hydroclimate during the last millennium. Earth Syst Dyn 7(3):681-696. https://doi.org/10. 5194/esd-7-681-2016 
Crutzen PJ (2006) Albedo enhancement by stratospheric sulfur injections: a contribution to resolve a policy dilemma? Clim Change 77:211. https://doi.org/10.1007/s10584-006-9101-y

Dee DP, Uppala SM, Simmons AJ, Berrisford P, Poli P, Kobayashi S, Andrae U, Balmaseda MA, Balsamo G, Bauer P, Bechtold P, Beljaars ACM, van de Berg L, Bidlot J, Bormann N, Delsol C, Dragani R, Fuentes M, Geer AJ, Vitart F (2011) The ERA-Interim reanalysis: configuration and performance of the data assimilation system. Q J R Meteorol Soc 137(656):553-597. https://doi.org/ 10.1002/qj. 828

Donnelly JP, Hawkes AD, Lane P, MacDonald D, Shuman BN, Toomey MR, van Hengstum PJ, Woodruff JD (2015) Climate forcing of unprecedented intense-hurricane activity in the last 2000 years. Earth's Fut 3(2):49-65. https://doi.org/10.1002/2014EF000274

Duan L, Cao L, Bala G, Caldeira K (2019) Climate response to pulse versus sustained stratospheric aerosol forcing. Geophys Res Lett 46:8976-8984. https://doi.org/10.1029/2019GL083701

Dyer AJ, Hicks BB (1970) Flux-gradient relationships in the constant flux layer. Q J R Meteorol Soc 96(410):715-721. https://doi.org/ 10.1002/qj.49709641012

Elsner JB (2006) Evidence in support of the climate change-Atlantic hurricane hypothesis. Geophys Res Lett. https://doi.org/10.1029/ 2006GL026869

Emanuel KA (2005) Increasing destructiveness of tropical cyclones over the past 30 years. Nature 436(7051):686-688. https://doi. org/10.1038/nature03906

Emanuel KA (2006) Climate and tropical cyclone activity: a new model downscaling approach. J Clim 19(19):4797-4802. https://doi.org/ 10.1175/JCLI3908.1

Emanuel KA (2013) Downscaling CMIP5 climate models shows increased tropical cyclone activity over the 21 st century. Proc Natl Acad Sci 110(30):12219-12224. https://doi.org/10.1073/ pnas. 1301293110

Emanuel KA, Nolan DS (2004) Tropical cyclone activity and the global climate system. In: 26th Conference on Hurricanes and Tropical Meteorology

Emanuel K, Solomon S, Folini D, Davis S, Cagnazzo C (2013) Influence of tropical Tropopause layer cooling on Atlantic hurricane activity. J Clim 26(7):2288-2301. https://doi.org/10.1175/ JCLI-D-12-00242.1

Evan AT (2012) Atlantic hurricane activity following two major volcanic eruptions. J Geophys Res Atmos. https://doi.org/10.1029/ 2011JD016716

Gao C, Robock A, Ammann C (2008) Volcanic forcing of climate over the past 1500 years: an improved ice core-based index for climate models. J Geophys Res Atmos. https://doi.org/10.1029/ 2008JD010239

Govindasamy B, Caldeira K (2000) Geoengineering earth's radiation balance to mitigate $\mathrm{CO} 2$-induced climate change. Geophys Res Lett 27(14):2141-2144. https://doi.org/10.1029/1999GL006086

Guevara-Murua A, Hendy EJ, Rust AC, Cashman KV (2015) Consistent decrease in North Atlantic Tropical Cyclone frequency following major volcanic eruptions in the last three centuries. Geophys Res Lett 42(21):9425-9432. https://doi.org/10.1002/ 2015GL066154

Haywood JM, Jones A, Bellouin N, Stephenson D (2013) Asymmetric forcing from stratospheric aerosols impacts Sahelian rainfall. Nat Clim Change 3(7):660-665. https://doi.org/10.1038/nclimate1857

Hodges K, Cobb A, Vidale PL (2017) How well are tropical cyclones represented in reanalysis datasets? J Clim 30(14):5243-5264. https://doi.org/10.1175/JCLI-D-16-0557.1

Hong S, Lim J (2006) The WRF single-moment 6-class microphysics scheme (WSM6). Asia-Pac J Atmos Sci 42:129-151

Hong S-Y, Noh Y, Dudhia J (2006) A new vertical diffusion package with an explicit treatment of entrainment processes. Mon Weather Rev 134(9):2318-2341. https://doi.org/10.1175/MWR3199.1
Horn M, Walsh K, Zhao M, Camargo SJ, Scoccimarro E, Murakami H, Wang H, Ballinger A, Kumar A, Shaevitz DA, Jonas JA, Oouchi K (2014) Tracking scheme dependence of simulated tropical cyclone response to idealized climate simulations. J Clim 27(24):9197_ 9213. http://www.jstor.org/stable/26194640

Iacono MJ, Delamere JS, Mlawer EJ, Shephard MW, Clough SA, Collins WD (2008) Radiative forcing by long-lived greenhouse gases: calculations with the AER radiative transfer models. J Geophys Res Atmos. https://doi.org/10.1029/2008JD009944

IPCC (2014) Climate change 2014: synthesis report. Contribution of working groups I, II and III to the fifth assessment report of the intergovernmental panel on climate change. https://www.ipcc.ch/ report/ar5/syr/

IPCC (2018) Global warming of 1.5 degrees celsius: An IPCC special report on the impacts of global warming of 1.5 degrees $\mathrm{c}$ above pre-industrial levels and related global greenhouse gas emission pathways, in the context of strengthening the global response to the thr.

Jones AC, Haywood JM, Dunstone N, Emanuel K, Hawcroft MK, Hodges KI, Jones A (2017) Impacts of hemispheric solar geoengineering on tropical cyclone frequency. Nat Commun 8:1382. https://doi.org/10.1038/s41467-017-01606-0

Kain JS (2004) The Kain-Fritsch convective parameterization: an update. J Appl Meteorol 43(1):170-181. https://doi.org/10.1175/ 1520-0450(2004)043\%3c0170:TKCPAU\%3e2.0.CO;2

King RO (2013) Financing natural catastrophe exposure: issues and options for improving risk transfer markets. Congressional Research Service, Library of Congress, $\mathrm{p} 30$

Knapp KR, Kruk MC, Levinson DH, Diamond HJ, Neumann CJ (2010) The international best track archive for climate stewardship (IBTrACS): unifying tropical cyclone data. Bull Am Meteorol Soc 91(3):363-376. https://doi.org/10.1175/2009BAMS2755.1

Knutson T, Sirutis J, Garner S, Vecchi G, Held I (2008) Erratum: Simulated reduction in Atlantic hurricane frequency under twenty-firstcentury warming conditions. Nat Geosci 1(7):479. https://doi.org/ 10.1038/ngeo229

Knutson TR, McBride JL, Chan J, Emanuel K, Holland G, Landsea C, Held I, Kossin JP, Srivastava AK, Sugi M (2010) Tropical cyclones and climate change. Nat Geosci 3(3):157-163. https:// doi.org/10.1038/ngeo779

Korty RL, Camargo SJ, Galewsky J (2012) Tropical cyclone genesis factors in simulations of the last glacial maximum. J Clim 25(12):4348-4365. https://doi.org/10.1175/JCLI-D-11-00517.1

Korty RL, Emanuel KA, Huber M, Zamora RA (2017) Tropical cyclones downscaled from simulations with very high carbon dioxide levels. J Clim 30(2):649-667. https://doi.org/10.1175/ JCLI-D-16-0256.1

Kossin JP, Knapp KR, Olander TL, Velden CS (2020) Global increase in major tropical cyclone exceedance probability over the past four decades. Proc Natl Acad Sci 117(22):11975-11980. https://doi. org/10.1073/pnas.1920849117

Kozar ME, Mann ME, Emanuel KA, Evans JL (2013) Long-term variations of North Atlantic tropical cyclone activity downscaled from a coupled model simulation of the last millennium. J Geophys Res Atmos 118(24):13313-383392. https://doi.org/10.1002/2013J D020380

Kravitz B, MacMartin DG, Robock A, Rasch PJ, Ricke KL, Cole JNS, Curry CL, Irvine PJ, Ji D, Keith DW, Kristjánsson JE, Moore JC, Muri H, Singh B, Tilmes S, Watanabe S, Yang S, Yoon J-H (2014) A multi-model assessment of regional climate disparities caused by solar geoengineering. Environ Res Lett 9(7):74013. https://doi. org/10.1088/1748-9326/9/7/074013

Lacis AA, Mishchenko MI (1995) Climate forcing, climate sensitivity, and climate response: a radiative modelling perspective on atmospheric aerosols. In: Charlson RJ, Heinztenberg J (eds) Aerosol forcing of climate. Wiley, Chichester, pp 11-42 (416) 
Liu K, Lu H, Shen C (2008) A 1200-year proxy record of hurricanes and fires from the Gulf of Mexico coast: testing the hypothesis of hurricane-fire interactions. Quat Res 69(1):29-41. https://doi.org/ 10.1016/j.yqres.2007.10.011

Lui YS, Tse LKS, Tam CY et al (2021) Performance of MPAS-A and WRF in predicting and simulating western North Pacific tropical cyclone tracks and intensities. Theoretical Applied Climatology 143:505-520. https://doi.org/10.1007/s00704-020-03444-5

MacMartin DG, Wang W, Kravitz B, Tilmes S, Richter JH, Mills MJ (2019) Timescale for detecting the climate response to stratospheric aerosol geoengineering. J Geophys Res Atmos 124(3):1233-1247. https://doi.org/10.1029/2018JD028906

Mann ME, Woodruff JD, Donnelly JP, Zhang Z (2009) Atlantic hurricanes and climate over the past 1500 years. Nature 460(7257):880-883. https://doi.org/10.1038/nature08219

Mass CF, Portman DA (1989) Major volcanic eruptions and climate: a critical evaluation. J Clim 2(6):566-593. https://doi.org/10.1175/ 1520-0442(1989)002\%3c0566:MVEACA\%3e2.0.CO;2

Msadek R, Vecchi GA, Knutson TR (2013) North atlantic hurricane activity: past, present and future. Climate change: multidecadal and beyond, vol 6. World scientific, pp 285-301. https://doi.org/ 10.1142/9789814579933_0018

Oliva F, Viau AE, Peros MC, Bouchard M (2018) Paleotempestology database for the western North Atlantic basin. The Holocene 28(10):1664-1671. https://doi.org/10.1177/0959683618782598

Otto-Bliesner BL, Brady EC, Fasullo J, Jahn A, Landrum L, Stevenson S, Rosenbloom N, Mai A, Strand G (2016) Climate variability and change since $850 \mathrm{CE}$ : an ensemble approach with the community earth system model. Bull Am Meteorol Soc 97(5):735-754. https://doi.org/10.1175/BAMS-D-14-00233.1

Paulson CA (1970) The mathematical representation of wind speed and temperature profiles in the unstable atmospheric surface layer. $\mathrm{J}$ Appl Meteorol Climatol 9(6):857-861. https://doi.org/10.1175/ 1520-0450(1970)009

Pausata FS, Camargo SJ (2019) Tropical cyclone activity affected by volcanically induced ITCZ shifts. Proc Natl Acad Sci 116(16):7732-7737

Pollard RT, Rhines PB, Thompson RORY (1973) The deepening of the wind-Mixed layer. Geophys Fluid Dyn 4(4):381-404. https://doi. org/10.1080/03091927208236105

Raible CC, Brönnimann S, Auchmann R, Brohan P, Frölicher TL, Graf H-F, Jones P, Luterbacher J, Muthers S, Neukom R, Robock A, Self S, Sudrajat A, Timmreck C, Wegmann M (2016) Tambora 1815 as a test case for high impact volcanic eruptions: Earth system effects. Wires Clim Change 7(4):569-589. https://doi.org/10. $1002 /$ wcc. 407

Robock A (2000) Volcanic eruptions and climate. Rev Geophys 38(2):191-219. https://doi.org/10.1029/1998RG000054

Robock A (2015) Climate and climate change: volcanoes: role in climate. Encyclopedia of atmospheric sciences, 2nd edn. Elsevier Inc, pp 105-111

Schenkel BA, Hart RE (2011) An examination of tropical cyclone position, intensity, and intensity life cycle within atmospheric reanalysis datasets. J Clim 25(10):3453-3475. https://doi.org/10. 1175/2011JCLI4208.1

Schmidt GA, Jungclaus JH, Ammann CM, Bard E, Braconnot P, Crowley TJ, Delaygue G, Joos F, Krivova NA, Muscheler R, OttoBliesner BL, Pongratz J, Shindell DT, Solanki SK, Steinhilber F, Vieira LEA (2012) Climate forcing reconstructions for use in PMIP simulations of the Last Millennium (v1.1). Geosci Model Dev 5(1):185-191. https://doi.org/10.5194/gmd-5-185-2012

Schurer AP, Hegerl GC, Mann ME, Tett SFB, Phipps SJ (2013) Separating forced from chaotic climate variability over the past millennium. J Clim 26(18):6954-6973. https://doi.org/10.1175/ JCLI-D-12-00826.1
Schurer AP, Tett SFB, Hegerl GC (2014) Small influence of solar variability on climate over the past millennium. Nat Geosci 7(2):104108. https://doi.org/10.1038/ngeo2040

Skamarock WC, Klemp JB, Dudhia J, Gill DO, Barker DM, Duda MG, Huang X-Y, Wang W, Powers JG (2008) A description of the advanced research WRF Version 3. https://doi.org/10.5065/ D68S4MVH

Stevenson S, Fasullo JT, Otto-Bliesner BL, Tomas RA, Gao C (2017) Role of eruption season in reconciling model and proxy responses to tropical volcanism. Proc Natl Acad Sci 114(8):1822-1826. https://doi.org/10.1073/pnas.1612505114

Strauss BH, Orton PM, Bittermann K et al (2021) Economic damages from Hurricane Sandy attributable to sea level rise caused by anthropogenic climate change. Nat Commun 12:2720. https:// doi.org/10.1038/s41467-021-22838-1

Swingedouw D, Mignot J, Ortega P, Khodri M, Menegoz M, Cassou C, Hanquiez V (2017) Impact of explosive volcanic eruptions on the main climate variability modes. Global Planet Change 150:24-45. https://doi.org/10.1016/j.gloplacha.2017.01.006

Tang B, Camargo SJ (2014) Environmental control of tropical cyclones in CMIP5: a ventilation perspective. J Adv Model Earth Syst 6(1):115-128. https://doi.org/10.1002/2013MS000294

Tewari M, Chen F, Wang W, Dudhia J, LeMone MA, Mitchell K, Ek M, Gayno G, Wegiel J, Cuenca RH (2004) Implementation and verification of the unified Noah land surface model in the WRF model. In: 20th Conference on Weather Analysis and Forecasting/16th Conference on Numerical Weather Prediction

Ting M, Camargo SJ, Li C, Kushnir Y (2015) Natural and forced North Atlantic hurricane potential intensity change in CMIP5 models. J Clim 28(10):3926-3942. https://doi.org/10.1175/ JCLI-D-14-00520.1

Vecchi GA, Landsea C, Zhang W, Villarini G, Knutson T (2021) Changes in Atlantic major hurricane frequency since the late19th century. Nat Commun 12(1):4054. https://doi.org/10.1038/ s41467-021-24268-5

Villarini G, Vecchi GA (2013) Projected increases in North Atlantic tropical cyclone intensity from CMIP5 models. J Clim 26(10):3231-3240. https://doi.org/10.1175/JCLI-D-12-00441.1

Walsh KJE, Camargo SJ, Vecchi GA, Daloz AS, Elsner J, Emanuel K, Horn M, Lim Y-K, Roberts M, Patricola C, Scoccimarro E, Sobel AH, Strazzo S, Villarini G, Wehner M, Zhao M, Kossin JP, LaRow T, Oouchi K, Henderson N (2015) Hurricanes and climate: the US CLIVAR Working Group on Hurricanes. Bull Am Meteorol Soc 96(6):997-1017. https://doi.org/10.1175/ BAMS-D-13-00242.1

Wang Q, Moore JC, Ji D (2018) A statistical examination of the effects of stratospheric sulfate geoengineering on tropical storm genesis. Atmos Chem Phys 18(13):9173-9188. https://doi.org/10.5194/ acp-18-9173-2018

Webb EK (1970) Profile relationships: the log-linear range, and extension to strong stability. Q J R Meteorol Soc 96(407):67-90. https:// doi.org/10.1002/qj.49709640708

Wehner M, Prabhat A, Reed KA, Stone D, Collins WD, Bacmeister J (2015) Resolution dependence of future tropical cyclone projections of CAM51 in the US CLIVAR hurricane working group idealized configurations. J Clim 28(10):3905-3925. https://doi. org/10.1175/JCLI-D-14-00311.1

Wilson JC et al (1993) In-situ observations of aerosol and chlorine monoxide after the 1991 eruption of Mount Pinatubo: effect of reactions on sulfate areosol. Science 261:1140-1143

Yan Q, Korty R, Zhang Z (2015) Tropical cyclone genesis factors in a simulation of the last two millennia: results from the community earth system model. J Clim 28(18):7182-7202. https://doi.org/10. 1175/JCLI-D-15-0054.1 
Yan Q, Zhang Z, Wang H (2018) Divergent responses of tropical cyclone genesis factors to strong volcanic eruptions at different latitudes. Clim Dyn 50(5):2121-2136. https://doi.org/10.1007/ s00382-017-3739-1

Yang W, Vecchi G, Fueglistaler S, Horowitz LW, Luet DJ, Muñoz ÁG et al (2019) Climate impacts from large volcanic eruptions in a high-resolution climate model: the importance of forcing structure. Geophys Res Lett. https://doi.org/10.1029/2019GL082367
Zhao M, Held IM, Lin S-J, Vecchi GA (2009) Simulations of global hurricane climatology, interannual variability, and response to global warming using a $50-\mathrm{km}$ resolution GCM. J Clim 22(24):6653-6678. https://doi.org/10.1175/2009JCLI3049.1

Publisher's Note Springer Nature remains neutral with regard to jurisdictional claims in published maps and institutional affiliations. 